\title{
1, 25-dihydroxy-vitamin D3 with tumor necrosis factor-alpha protects against rheumatoid arthritis by promoting p53 acetylation-mediated apoptosis via Sirt1 in synoviocytes
}

Xin $\mathrm{Gu}^{1,4}$, Bingjie Gu, ${ }^{2,4}$, Xianhui Lv ${ }^{1}$, Zhenzhen $\mathrm{Yu}^{1}$, Rong Wang ${ }^{1}$, Xiaoli Zhou', Wanxin Qiao', Zhiyuan Mao ${ }^{1}$, Guoping Zuo ${ }^{1}$, Qing Li ${ }^{3}$, Dengshun Miao ${ }^{1}$ and Jianliang Jin ${ }^{*, 1}$

Impaired apoptosis of fibroblast-like synoviocytes (FLSs) causes synovial hyperplasia, facilitating destruction of cartilage and bone in rheumatoid arthritis (RA). Tumor necrosis factor (TNF)- $\alpha$, a dominant inflammatory mediator in RA pathogenesis, promotes progression of RA symptoms. Prevalence of 1, 25-dihydroxy-vitamin $D_{3}$ (hereafter termed VD) deficiency is $30-63 \%$ in patients with RA. Whether VD leads to apoptosis or enhances TNF- $\alpha$-mediated apoptosis in FLSs to ameliorate RA is unclear. To determine this, 10-week-old CYP27B1-deficient $\left(\mathrm{CYP}^{2} \mathrm{BB}^{-1-}\right)$ mice with collagen-induced arthritis (CIA) were intraperitoneally treated with $1 \mu \mathrm{g} / \mathrm{kg}$ VD every other day for 9 weeks. RA phenotypes were compared between vehicle-treated $C Y P 27 B 1^{-/-}$and wildtype CIA mice. Human rheumatoid FLS-MH7A cells were treated with Dulbecco's modified Eagle's medium (DMEM) without fetal bovine serum (FBS) for $24 \mathrm{~h}$, then with different concentrations of VD and TNF- $\alpha$, human vitamin D receptor (VDR) siRNA or the p53 pro-apoptotic inhibitor pifithrin- $\alpha$. Apoptosis and p53 pro-apoptotic signaling were analyzed. The 19-week-old vehicle-treated $\mathrm{CYP}^{2} \mathrm{BB}^{-1-} \mathrm{ClA}$ mice had increased cumulative arthritis scores and levels of serous rheumatoid factors and C-reactive protein. They had exacerbated articular cartilage and bone destruction, joint space narrowing, joint stiffness, deformity and dysfunction, synovitis and TNF- $\alpha$ secretion, FLS hyperplasia with increased proliferation and decreased apoptosis compared to CIA mice. These RA phenotypes that were aggravated in CIA mice by CYP27B1 deficiency were largely rescued by VD treatment. In vitro, VD with TNF- $\alpha$ treatment upregulated p53 acetylation-mediated apoptosis in MH7A cells by promoting Sirt1 translocation from the nucleus to the cytoplasm. These findings indicated that VD with TNF- $\alpha$ protected against RA by promoting apoptosis of FLSs. The results indicated that clinical administration of VD could be a specific therapy to promote FLS apoptosis and prevent RA progression.

Cell Death and Disease (2016) 7, e2423; doi:10.1038/cddis.2016.300; published online 20 October 2016

Rheumatoid arthritis (RA) is chronic synovial inflammation and fibroblast-like synoviocytes (FLSs) hyperplasia with subsequent destruction of articular cartilage and bone, joint swelling and space narrowing, and joint stiffness, deformity and dysfunction. These are the main pathological features of autoimmune diseases, which mostly invade multiple small, symmetrical joints of the hands and feet. RA affects up to $1 \%$ of adults worldwide. ${ }^{1-3}$ FLSs, in particular, are key in RA because they produce cytokines that perpetuate inflammation and proteases. ${ }^{4}$ Impaired apoptosis of FLSs is mainly the result of abnormal p53 pro-apoptotic signaling that results in changes in the composition and structure of the inflamed synovial membrane. ${ }^{5,6}$ These changes cause the development of synovial hyperplasia and extend the life span of these FLSs, facilitating the destruction of cartilage and bone in RA. ${ }^{3,4,7}$
A previous clinical investigation showed that tumor necrosis factor-alpha (TNF-a), a dominant inflammatory mediator in RA pathogenesis, is highly expressed in synovial fluid in RA. Selectively blocking TNF- $a$ alleviates the progression of RA symptoms., ${ }^{8,9}$ However, whether TNF-a mediates antiapoptosis or pro-apoptosis pathogenic responses in RA-FLSs is unknown. ${ }^{10,11}$ Previous evidence supports that TNF- $a$ inhibits pro-apoptosis by Bcl-2 family members in RA-FLS. ${ }^{7}$ However, several lines of evidence suggest that the binding of TNF- $a$ to its cell surface receptor TNF-R1 could induce pro-apoptotic responses to FLSs. Methods for enhancing the TNF- $a$-mediated apoptotic effects on RA FLSs have not been determined. ${ }^{11,12}$

The compound VD is considered to maintain homeostasis of calcium-phosphorus metabolism. ${ }^{13}$ However, recent studies suggest that VD may be important in preventing

\footnotetext{
${ }^{1}$ Research Centre for Bone and Stem Cells, Department of Human Anatomy, Histology and Embryology, Nanjing Medical University, Nanjing, Jiangsu 211166, China; ${ }^{2}$ Department of Rheumatology and Immunology, Nanjing First Hospital; Nanjing Medical University, Nanjing, Jiangsu 210000, China and ${ }^{3}$ Jiangsu Jiankang Vocational College, Nanjing, Jiangsu 210029, China

*Corresponding author: J Jin, Research Centre for Bone and Stem Cells; Department of Anatomy, Histology and Embryology, Nanjing Medical University, No.101, Longmian Avenue, Jiangning District, Nanjing, Jiangsu 211166, China. Tel: +86 25 86869377; Fax: +86 25 86869443; E-mail: jinjianliang@njmu.edu.cn

${ }^{4}$ These authors contributed equally to this work and should be considered co-first authors.

Abbreviations: VD, 1, 25-dihydroxy-vitamin D3; RA, rheumatoid arthritis; TNF- $\alpha$, tumor necrosis factor- $\alpha$; FLSs, fibroblast like synoviocytes Received 06.5.16; revised 14.8.16; accepted 25.8.16; Edited by Y Shi
} 
A

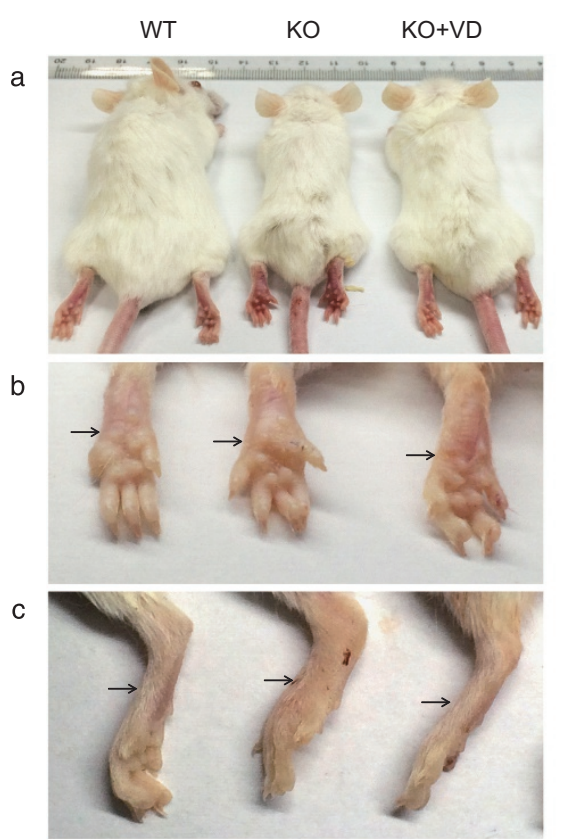

C

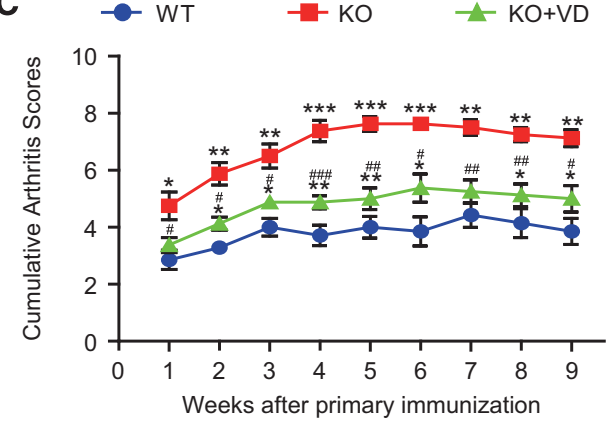

$\square$ WT $\square$ KO $\square$ KO+VD

D

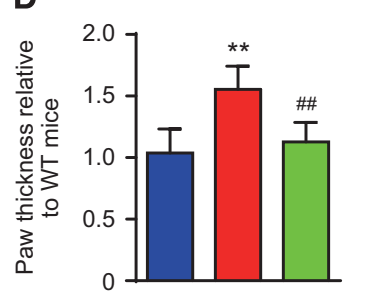

E

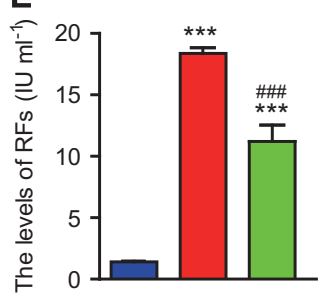

$\mathbf{F}$

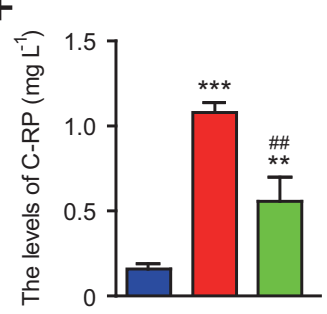

autoimmune diseases. ${ }^{13-15}$ Emerging clinical epidemiology evidence indicates that the prevalence of VD deficiency is 30$63 \%$ in people with RA, serum VD levels negatively correlate with RA activity, and VD supplements are a beneficial RA treatment. ${ }^{2,14}$ Data show that VD upregulates TNF- $\alpha$ -
B

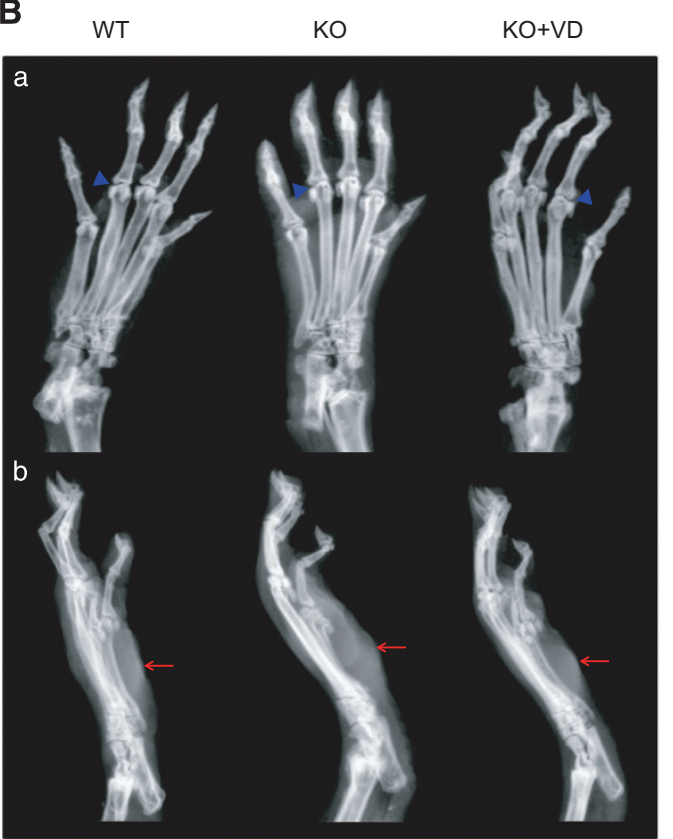

G

KO

$\mathrm{KO}+\mathrm{VD}$

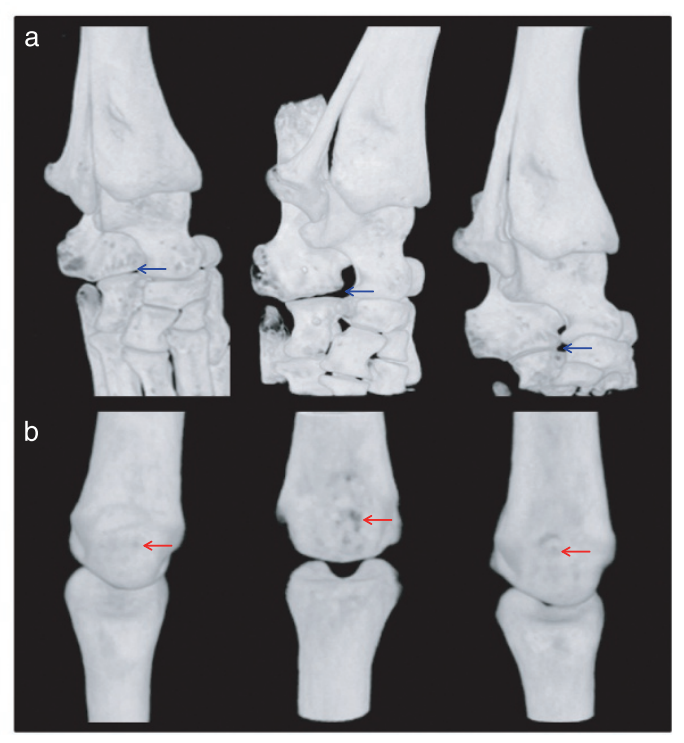

mediated pro-apoptotic effects in prostate tumor cells and osteoblasts and down-regulates pro-inflammatory effects in RA macrophages and T cells. ${ }^{12,16}$ However, whether VD leads to apoptosis or enhances TNF- $a$-mediated apoptosis in FLSs to ameliorate RA is unclear. 
Figure 1 VD improved clinical indexes of rheumatoid arthritis in CYP27B1 ${ }^{-/-}$CIA mice. (Aa) Representative appearance and (Ab) underside and (Ac) side of arthritic hind palms from 19-week-old wild type (WT), CYP27B1 ${ }^{-/-}(\mathrm{KO})$ and KO+VD CIA mice. Black arrows: hind palms. (b) Representative radiographs of (Ba) underside and (Bb) side of arthritic hind palms. Blue arrowhead: interphalangeal joints of arthritic hind palms; red arrow: hind palms. (c) Cumulative arthritis scores for subjective evaluation of arthritis severity of arthritic hind palms from 1 to 9 weeks after primary immunization. (d) Paw thickness relative to WT mice. (e) Levels of rheumatoid factors (RFs) and (f) C-reactive protein (C-RP) in serum determined by spectrophotometry. Values are mean \pm S.E.M. of six determinations per group. ${ }^{\star} P<0.05 ;{ }^{* \star} P<0.01 ;{ }^{* \star \star} P<0.001$ compared with WT group at the same age. ${ }^{\#} P<0.05 ;{ }^{\# \#} P<0.01$; ${ }^{\# \#} P<0.001$ compared with $\mathrm{KO}$ group at the same age. (g) Representative $3 \mathrm{D}$-reconstructed images of (Ga) intertarsal joint and (Gb) interphalangeal joints of arthritic hind palms. Blue arrow: deformity of intertarsal joints; red arrow: bone erosion of phalanxes

The pathological features of collagen-induced arthritis (CIA) in mice are consistent with typical pathological alterations in $\mathrm{RA}$ patients. Therefore, CIA is the most widely studied RA model. $^{9}$

We induced CIA in CYP27B1-deficient $\left(C Y P 27 B 1^{-1-}\right)$ mice, and intraperitoneally injected them with $1 \mu \mathrm{g} / \mathrm{kg}$ VD every other day. Their RA phenotypes were compared with vehicle-treated CYP $27 B 1^{-1-}$ and wild-type (WT) CIA mice. We treated human rheumatoid FLS-MH7A cells with different concentrations of VD, TNF- $a$ and human VDR siRNA and the p53 pro-apoptotic inhibitor pifithrin- $a$. Apoptosis and p53 pro-apoptotic signaling were analyzed.

\section{Results}

Levels of serum VD in VD-treated CYP27B1 $^{-1-}$ CIA mice restored to normal. Radioimmunoassay showed that serum VD levels in 10-week-old CYP27B1 ${ }^{-1-}$ mice or 19-week-old vehicle-treated $C Y P 27 B 1^{-1-} \mathrm{CIA}$ mice were significantly decreased compared to those in 10-week-old WT or 19-week-old WT CIA mice, respectively. We confirmed that serum VD levels of 19-week-old VD-treated CYP27B1-1- CIA mice were restored to normal (Supplementary Figure S1A).

To compare the serum VD levels between VD-treated WT mice and vehicle-treated WT mice, 10-week-old male WT mice were intraperitoneally injected with $1 \mu \mathrm{g} / \mathrm{kg}$ VD or vehicle every other day for 3 weeks. The levels of serum VD did not differ between 13-week-old VD-treated and vehicle-treated WT mice (Supplementary Figure S1A). It demonstrated that VD supplement did not increase serum level of VD in healthy individuals with sufficient VD.

Clinical indexes of rheumatoid arthritis were ameliorated in CYP27B1 $^{-1-}$ CIA mice by VD. To assess if VD treatment ameliorated clinical indexes of RA in CYP27B1 ${ }^{-/} \mathrm{CIA}$ mice, arthritis severity, swelling degree, rheumatoid serum biochemical measurements, and bone and joint erosion of arthritic hind palms were subjectively evaluated in 19-weekold, VD-treated CYP27B1 ${ }^{-/} \mathrm{CIA}$, vehicle-treated CYP27B1 $1^{-/}$ and WT CIA mice. Compared with WT CIA mice, body size was decreased; however, cumulative arthritis scores from 1 to 9 weeks after primary immunization, paw thickness, levels of rheumatoid factors (RFs) and C-reactive protein (C-RP) from serum increased significantly in vehicle-treated CYP27B1 ${ }^{-1-}$ CIA mice (Figures 1a-f). X-ray and threedimensional (3D) reconstructed graphs of hind palms showed that metatarsophalangeal joints were characterized by blurred articular surface, cartilage erosion and narrowed articular space on radiographs; intertarsal joints showed deformity and phalanxes were eroded on 3D-reconstructed graphs (Figures $1 \mathrm{~b}$ and $\mathrm{g}$ ). Compared with vehicle-treated CYP27B1 ${ }^{-1-}$ CIA mice, body size was increased; however, cumulative arthritis scores from 1 to 9 weeks after primary immunization, paw thickness, and RFs and C-RP serum levels decreased significantly in VD-treated $C Y P 27 B 1^{-1-}$ mice (Figures 1a-f). The VD treatment ameliorated the arthritic characteristics of metatarsophalangeal joints and intertarsal joints, and decreased bony erosion of phalanxes in VD-treated CYP27B1 ${ }^{-/}$CIA mice (Figures $1 \mathrm{~b}$ and $\mathrm{g}$ ).

Histological bone destruction, cartilage erosion and synovial inflammation of rheumatoid arthritis were ameliorated in CYP27B1 ${ }^{-/}$CIA mice by VD. To investigate if VD treatment ameliorated histological bone destruction, cartilage erosion and synovial inflammation of RA in CYP27B1-1- CIA mice, HE, total collagen, and Safranin O and fast green double dyeing (SO-FG) histochemical staining were performed to analyze trabecular and cartilage volume. TNF- $\alpha$, IL-1 $\beta$, CD3 and F4/80 immunohistochemical staining for synovial inflammation were performed. Compared with WT CIA mice, trabecular and cartilage bone volume decreased significantly; however, percentages of TNF-a, $\mathrm{IL}-1 \beta, \mathrm{CD} 3$ and $\mathrm{F} 4 / 80$ positive inflammatory cells in FLSs increased in vehicle-treated $C Y P 27 B 1^{-1-} \mathrm{CIA}$ mice (Figure 2). Compared with vehicle-treated $C Y P 27 B 1^{-1-} \mathrm{CIA}$ mice, trabecular and cartilage bone volume increased significantly; however, percentages of TNF- $a, \mathrm{IL}-1 \beta$, CD3 and $\mathrm{F} 4 / 80$-positive inflammatory cells in synovial membranes decreased in VD-treated CYP27B1 ${ }^{-1-}$ CIA mice (Figure 2).

Synovial hyperplasia caused by increased FLS proliferation and decreased apoptosis were ameliorated in CYP27B1 $^{-/}$CIA mice by VD. To determine if VD treatment ameliorated synovial hyperplasia in CYP27B1-/- CIA mice, HE staining was used for comparisons with WT CIA mice. The number of synovial cells increased in vehicletreated $C Y P 27 B 1^{-1-}$ mice. Compared with vehicle-treated $C Y P 27 B 1^{-1-} \mathrm{CIA}$ mice, the number of synovial cells decreased in VD-treated CYP27B1 ${ }^{-1-}$ CIA mice (Figures 3a and e).

To further determine if VD treatment decreased proliferation

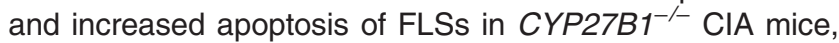
proliferating cell nuclear antigen (PCNA) immunohistochemistry staining was used to detect proliferation, and Caspase 3 staining and TUNEL assays were used to analyze apoptosis. Compared to WT CIA mice, the percentage of PCNA-positive FLSs decreased and percentages of Caspase3-positive and TUNEL-positive FLSs significantly increased in CYP27B1 ${ }^{-1-} \mathrm{ClA}$ mice; the percentage of PCNA-positive FLSs increased with a significant increase in percentages of 

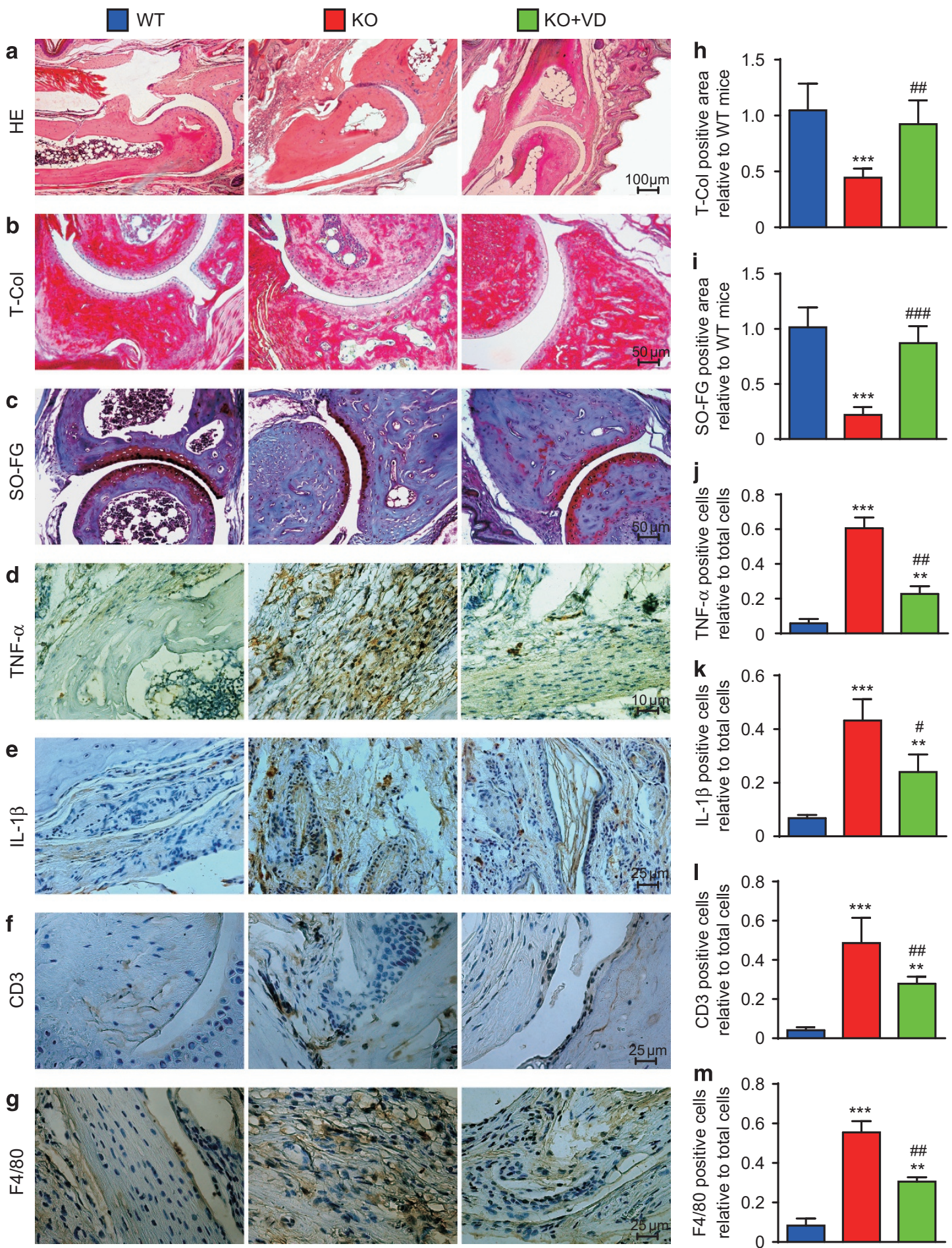

Figure 2 VD improved histological bone destruction, cartilage erosion and synovial inflammation of rheumatoid arthritis in CYP27B1 $1^{-/-}$CIA mice. (a) Representative micrographs of interphalangeal joints sections stained with HE from 19-week-old wild type (WT), CYP27B1 ${ }^{-1}$ (KO) and KO+VD CIA mice. Representative micrographs of paraffin-embedded sections stained histochemically for (b) total collagen (T-col) and (c) Safranin $\mathrm{O}$ and fast green double dyeing (SO-FG). Representative micrographs of paraffin-embedded sections stained immunohistochemically for (d) TNF- $\alpha$, (e) IL-1 $\beta$, (f) CD3 and (g) F4/80. (h-i) T-Col-positive and SO-FG-positive areas relative to WT mice in sections stained for figures $\mathbf{b}-\mathbf{c}$. Percentage of cells positive for (j) TNF- $\alpha,(\mathbf{k}) \mathrm{IL}-1 \beta$, (I) CD3 or (m) F4/80 relative to total cells in sections stained for figures $\mathbf{d}-\mathbf{g}$. Values are mean \pm S.E.M. of six determinations of each group. ${ }^{\star \star} P<0.01 ;{ }^{* \star \star} P<0.001$ compared with WT. ${ }^{\#} P<0.05 ;{ }^{\# \#} P<0.01 ; \# \#{ }^{\# \#} P<0.001$ compared with KO 

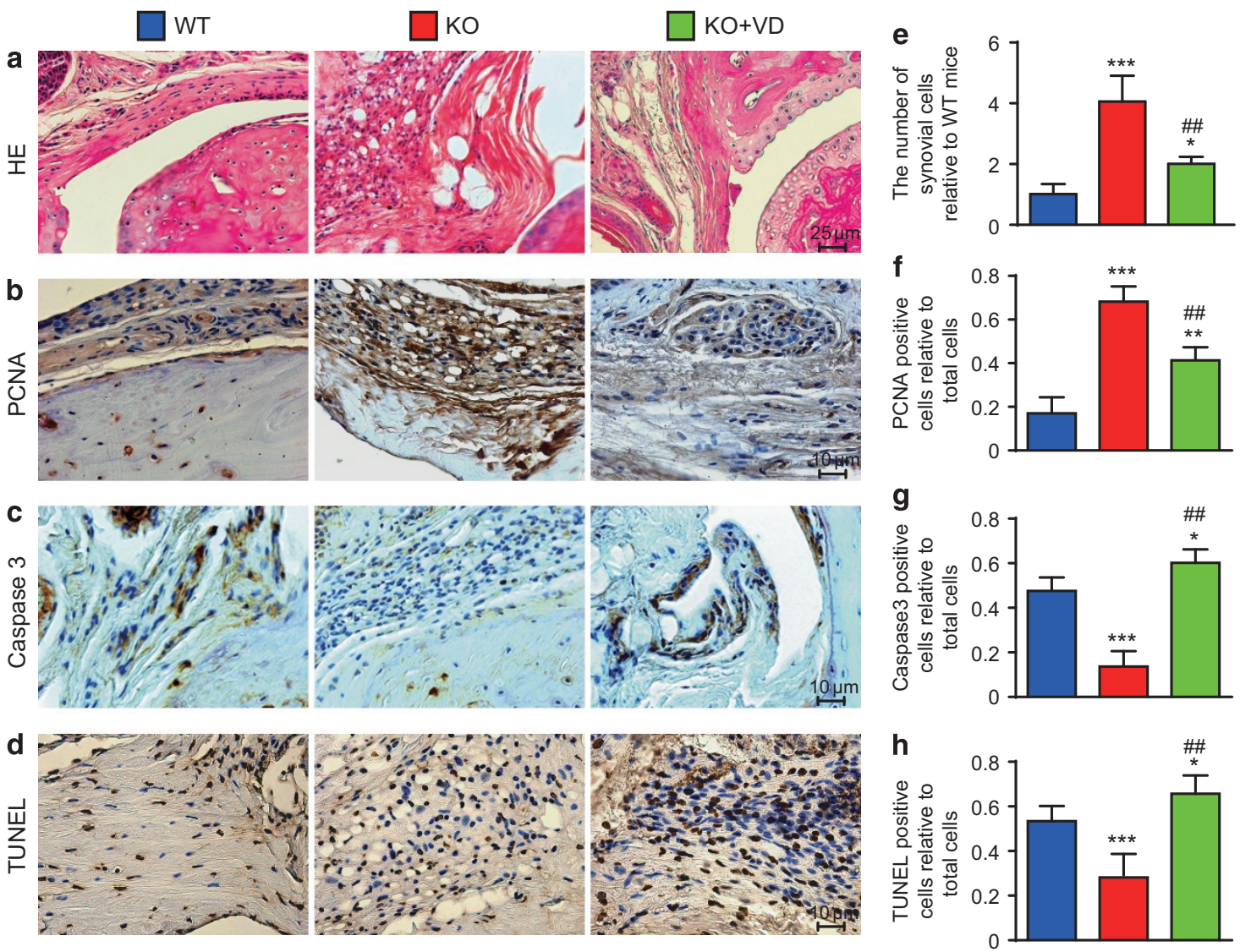

Figure 3 VD decreased proliferation and increased apoptosis of FLSs in CYP27B1 $1^{-1}$ CIA mice. Representative micrographs of sections of paraffin-embedded interphalangeal joints from 19-week-old wild type (WT), CYP27B1- ${ }^{--}$(KO) and KO+VD CIA mice stained for (a) HE, and immunohistochemically for (b) PCNA, (c) Caspase3 and (d) TUNEL. (e) The number of FLSs relative to WT mice was determined in HE-stained sections. The percentage of (f) PCNA-positive, (g) Caspase3-positive and (h) TUNELpositive cells relative to total cells was determined in stained sections in b-d. Values are mean \pm S.E.M. of six determinations per group. ${ }^{\star} P<0.05$; ${ }^{* \star} P<0.01$; ${ }^{\star \star \star} P<0.001$ compared with WT. ${ }^{\#} P<0.01$ compared with KO

Caspase3-positive and TUNEL-positive FLSs in VD-treated $C Y P 27 B 1^{-1}$ CIA mice. Compared with vehicle-treated CYP27B1 ${ }^{-1-}$ CIA mice, the percentage of PCNA-positive FLSs decreased and percentages of Caspase3-positive and TUNEL-positive FLSs significantly increased in VD-treated CYP27B1 ${ }^{--}$ClA mice (Figures 3b-d and f-h).

Apoptosis of human rheumatoid FLSs increased by VD with TNF- $\boldsymbol{a}$. To investigate if VD with TNF- $a$ promoted apoptosis of rheumatoid FLSs, human rheumatoid FLS$\mathrm{MH7A}$ cells were treated with different concentrations of VD and/or TNF-a. Apoptosis was detected by AV and PI double staining and flow cytometry. Results are shown in detail in Table 1. These results demonstrated that with TNF- $a$ treatment at the corresponding concentration, VD supplementation significantly increased the apoptosis of rheumatoid FLSs. Moreover, the pro-apoptotic effect of VD was increased with elevated concentrations of TNF- $a$ (Figures $4 a$ and b).

To detect further expression of pro-apoptotic and antiapoptotic genes, real-time RT-PCR were performed for Bcl-2 binding component 3 (also known as p53 upregulated modulator of apoptosis; PUMA), Bcl-2-associated X (Bax) protein and $\mathrm{BCl}-2$ (Table 1). These results demonstrated that with TNF- $a$ treatment at the corresponding concentration, VD supplementation significantly increased expression of proapoptotic genes and decreased expression of anti-apoptotic genes in rheumatoid FLSs. Moreover, under VD treatment at the corresponding concentration, expression of pro-apoptotic genes was increased with TNF- $a$ concentration. Expression of anti-apoptotic genes was decreased with increased TNF- $a$ concentration (Figures 4c-e).

Human rheumatoid FLS apoptosis after VD with TNF- $a$ was mediated by VDR and p53 pro-apoptotic signaling. To further investigate if apoptosis of rheumatoid FLSs induced by VD with TNF- $a$ treatment was mediated by VDR and p53 pro-apoptotic signaling, human rheumatoid FLSMH7A cells were knocked down with VDR siRNA.

Compared to negative control (NC) siRNA, VDR gene expression was downregulated to $17.87 \%$ in cells with VDR siRNA1, 52.52\% in cells with VDR siRNA2 and $30.24 \%$ in cells with siRNA3 (Supplementary Figure S1C). $\beta$-actin gene expression was downregulated to $36.4 \%$ in cells with $\beta$-actin siRNA, but was not altered in cells transfected with VDR 
siRNA1, 2 or 3 (Supplementary Figure S1D). VDR siRNA1 was for subsequent experiments. VDR protein expression was downregulated to $34.19 \%$ in cells with VDR siRNA1 compared to NC siRNA (Supplementary Figures S1E and S1F).
Cells were treated with VD and/or TNF- $a$ and p53 proapoptotic inhibitor PFT- $a$, and apoptosis detected by AV and PI double staining by flow cytometry. Detailed results are shown in Table 2. The pro-apoptotic effect induced by VD was

Table 1 VD with TNF-a promoted apoptosis of rheumatoid FLSs

\begin{tabular}{|c|c|c|c|c|c|c|}
\hline & $\begin{array}{c}\mathrm{AV}+\mathrm{PI}- \\
\text { cells }\end{array}$ & $\begin{array}{c}\mathrm{AV}+\mathrm{PI}+ \\
\text { cells }\end{array}$ & $\mathrm{AV}+$ cells & $\begin{array}{l}\text { PUMA } \\
\text { mRNA } \\
\text { levels }\end{array}$ & $\begin{array}{l}\text { Bax } \\
\text { mRNA } \\
\text { levels }\end{array}$ & $\begin{array}{c}\text { Bcl-2 } \\
\text { mRNA } \\
\text { levels }\end{array}$ \\
\hline $\begin{array}{l}\text { Serum } \\
\text { control }\end{array}$ & $\downarrow \downarrow \downarrow$ & $\downarrow \downarrow \downarrow$ & $\downarrow \downarrow \downarrow$ & $\downarrow \downarrow \downarrow$ & $\downarrow \downarrow$ & $\downarrow \downarrow \downarrow$ \\
\hline $\begin{array}{l}\text { Serum free } \\
\text { control }\end{array}$ & & & & & & \\
\hline $10^{-7} \mathrm{M}$ VD & $\uparrow \uparrow \uparrow$ & $\uparrow$ & $\uparrow \uparrow \uparrow$ & $\uparrow \uparrow \uparrow$ & $\uparrow \uparrow$ & $\downarrow$ \\
\hline $5 \times 10^{-8} \mathrm{M}$ VD & $\uparrow \uparrow \uparrow$ & - & $\uparrow \uparrow$ & $\uparrow \uparrow \uparrow$ & $\uparrow$ & - \\
\hline $10^{-8} \mathrm{M}$ VD & $\uparrow \uparrow$ & $\downarrow$ & $\uparrow$ & - & - & $\downarrow$ \\
\hline $\begin{array}{l}10 \mathrm{ng} \mathrm{ml}^{-1} \\
\text { TNF- } \alpha\end{array}$ & $\downarrow$ & $\downarrow \downarrow$ & $\downarrow \downarrow$ & - & $\downarrow$ & $\uparrow$ \\
\hline $\begin{array}{l}\text { 10ng ml } \\
\text { TNF- } \alpha \\
+10^{-7} \mathrm{M} \mathrm{VD}\end{array}$ & $\begin{array}{c}\uparrow \uparrow \uparrow \\
-\end{array}$ & $\begin{array}{l}\uparrow \uparrow \uparrow \\
\uparrow \uparrow \uparrow\end{array}$ & $\begin{array}{l}\uparrow \uparrow \uparrow \\
\uparrow \uparrow \uparrow\end{array}$ & $\begin{array}{c}\uparrow \uparrow \uparrow \\
\uparrow\end{array}$ & $\begin{array}{c}\uparrow \uparrow \uparrow \\
\uparrow \uparrow\end{array}$ & $\begin{array}{l}\downarrow \downarrow \\
\downarrow \downarrow\end{array}$ \\
\hline $\begin{array}{l}\text { 10 } \mathrm{ng} \mathrm{m}^{-1} \\
\text { TNF- } \alpha \\
+5 \times 10^{-8} \mathrm{M} \mathrm{VD}\end{array}$ & $\begin{array}{l}\uparrow \uparrow \uparrow \\
-\end{array}$ & $\begin{array}{l}\uparrow \uparrow \uparrow \\
\uparrow \uparrow \uparrow\end{array}$ & $\begin{array}{l}\uparrow \uparrow \uparrow \\
\uparrow \uparrow \uparrow\end{array}$ & $\begin{array}{c}\uparrow \uparrow \uparrow \\
\uparrow\end{array}$ & $\begin{array}{l}\uparrow \uparrow \\
\uparrow\end{array}$ & $\begin{array}{l}\downarrow \downarrow \downarrow \\
\downarrow \downarrow \downarrow\end{array}$ \\
\hline $\begin{array}{l}\text { 10ng ml } \\
\text { TNF- } \alpha \\
+10^{-8} \mathrm{M} \text { VD }\end{array}$ & $\begin{array}{c}\uparrow \uparrow \uparrow \\
\uparrow\end{array}$ & $\begin{array}{l}\uparrow \uparrow \uparrow \\
\uparrow \uparrow \uparrow\end{array}$ & $\begin{array}{l}\uparrow \uparrow \uparrow \\
\uparrow \uparrow \uparrow\end{array}$ & $\begin{array}{l}\uparrow \uparrow \\
\uparrow \uparrow\end{array}$ & $\begin{array}{l}\uparrow \\
\uparrow\end{array}$ & $\begin{array}{l}\downarrow \\
\downarrow\end{array}$ \\
\hline $\begin{array}{l}30 \mathrm{ng} \mathrm{ml}^{-1} \\
\mathrm{TNF}-\alpha\end{array}$ & $\downarrow$ & $\downarrow$ & $\downarrow$ & - & - & - \\
\hline $\begin{array}{l}\text { 30ng ml } \\
\text { TNF- } \alpha \\
+10^{-7} \mathrm{M} \text { VD }\end{array}$ & $\begin{array}{l}\uparrow \uparrow \uparrow \\
\uparrow \uparrow \uparrow \\
\uparrow \uparrow \uparrow\end{array}$ & $\begin{array}{l}\uparrow \uparrow \uparrow \\
\uparrow \uparrow \uparrow \\
\uparrow \uparrow \uparrow\end{array}$ & $\begin{array}{l}\uparrow \uparrow \uparrow \\
\uparrow \uparrow \uparrow \\
\uparrow \uparrow \uparrow\end{array}$ & $\begin{array}{c}\uparrow \uparrow \uparrow \\
\uparrow \uparrow \\
\uparrow\end{array}$ & $\begin{array}{l}\uparrow \uparrow \uparrow \\
\uparrow \uparrow \uparrow \\
\uparrow \uparrow\end{array}$ & $\begin{array}{l}\downarrow \downarrow \downarrow \\
\downarrow \downarrow \downarrow \\
\downarrow\end{array}$ \\
\hline $\begin{array}{l}\text { 30 } \mathrm{ng} \mathrm{ml}^{-1} \\
\mathrm{TNF}-\alpha \\
+5 \times 10^{-8} \mathrm{M} \text { VD }\end{array}$ & $\begin{array}{l}\uparrow \uparrow \uparrow \\
\uparrow \uparrow \uparrow \\
\uparrow \uparrow \uparrow\end{array}$ & $\begin{array}{l}\uparrow \uparrow \uparrow \\
\uparrow \uparrow \uparrow \\
\uparrow \uparrow \uparrow\end{array}$ & $\begin{array}{c}\uparrow \uparrow \uparrow \\
\uparrow \uparrow \uparrow \\
\uparrow\end{array}$ & $\begin{array}{c}\uparrow \uparrow \uparrow \\
\uparrow \uparrow \\
\uparrow\end{array}$ & $\begin{array}{c}\uparrow \uparrow \uparrow \\
\uparrow \uparrow \uparrow \\
\uparrow \uparrow\end{array}$ & $\begin{array}{l}\downarrow \downarrow \downarrow \\
\downarrow \downarrow \downarrow \\
-\end{array}$ \\
\hline $\begin{array}{l}\text { 30ng ml } \\
\text { TNF- } \alpha \\
+10^{-8} \text { M VD }\end{array}$ & $\begin{array}{l}\uparrow \uparrow \uparrow \\
\uparrow \uparrow \uparrow \\
\uparrow \uparrow \uparrow\end{array}$ & $\begin{array}{l}\uparrow \uparrow \uparrow \\
\uparrow \uparrow \uparrow \\
\uparrow \uparrow \uparrow\end{array}$ & $\begin{array}{l}\uparrow \uparrow \uparrow \\
\uparrow \uparrow \uparrow \\
\uparrow \uparrow \uparrow\end{array}$ & $\begin{array}{c}\uparrow \uparrow \uparrow \\
\uparrow \uparrow \uparrow \\
\uparrow\end{array}$ & $\begin{array}{l}\uparrow \uparrow \uparrow \\
\uparrow \uparrow \uparrow \\
\uparrow \uparrow\end{array}$ & $\begin{array}{c}\downarrow \downarrow \downarrow \\
\downarrow \downarrow \\
\downarrow\end{array}$ \\
\hline
\end{tabular}

Values are mean \pm SEM of six determinations per group. —: No difference; $\uparrow$ or $\downarrow$ : $\mathrm{P}<$ 0.05 ; $\uparrow$ or $\downarrow \downarrow$ : $\mathrm{P}<0.01$; $\uparrow \uparrow \uparrow$ or $\downarrow \downarrow \downarrow$ : $\mathrm{P}<0.001$ compared with serum-free control. —: No difference; $\uparrow$ or $\downarrow$ : $\mathrm{P}<0.05$; $\uparrow$ or $\downarrow \downarrow$ : $\mathrm{P}<0.01$; $\uparrow \uparrow \uparrow$ or $\downarrow \downarrow \downarrow: \mathrm{P}<0.001$ compared with the same concentration of VD. - : No difference; $\uparrow$ or $\downarrow: \mathrm{P}<0.05$; $\uparrow: \mathrm{P}<0.01$; $\uparrow \uparrow \uparrow: \mathrm{P}<0.001$ compared with $10 \mathrm{ng} \mathrm{ml}^{-1} \mathrm{TNF}-\alpha$ and the same concentration of VD. 
attenuated when VDR was knocked down or p53 was inhibited. Moreover, attenuation of the pro-apoptotic effect was more obvious in the p53-inhibited group than in VDRknocked down group (Figures $5 \mathrm{a}$ and $\mathrm{b}$ ).

To detect further expression of pro-apoptotic and antiapoptotic genes, real-time RT-PCR was performed for PUMA, Bax and BCl-2 (Table 2). When VDR was knocked down or p53 was inhibited, expression of the upregulated pro-apoptotic genes induced by VD was decreased, and expression of the downregulated anti-apoptotic gene induced by VD was increased. Moreover, the above changes were more obvious in the p53-inhibited group than in VDR-knocked down group (Figures 5c-e).

P53 acetylation-mediated apoptosis in human rheumatoid FLSs promoted by VD with TNF-a. To determine if VD with TNF- $a$ promoted p53 acetylation-mediated apoptosis in rheumatoid FLSs, western blots were performed for p53 acetylation-mediated apoptosis-related molecules (Table 3). These results demonstrated that with TNF- $a$ treatment at the corresponding concentration, VD supplementation significantly increased p53-acetylation-mediated apoptosis, including increased protein levels of Caspase 3, Bax, PUMA, p53 and p53 (acetyl K382), and decreased protein levels of Bcl-2. Moreover, with VD treatment at the corresponding concentration, p53-acetylation-mediated apoptosis increased with TNF- $a$ concentration (Figures 6a-g).

To determine if VD with TNF- $a$ inhibited p53-mediated proapoptotic effects by NF- $k$ B-p65 phosphorylation at Ser-536 in rheumatoid FLSs, western blotting was performed for expression of NF-kB-p65 and NF-kB-p65 (phospho S536) (Table 3). These results demonstrated that with TNF- $a$ treatment at the corresponding concentration, VD supplementation significantly decreased expression of NF- $k$ B-p65 and NF- $k$ B-p65 (phospho S536). Moreover, with VD treatment at the corresponding concentration, expression of NF- $k \mathrm{~B}-\mathrm{p} 65$ and NF- $k \mathrm{~B}-$ p65 (phospho S536) was decreased as TNF-a concentration increased (Figures 6a, h-i).

Sirt1 nuclei to cytoplasm translocation is promoted in human rheumatoid FLSs by VD with TNF-a. To determine if VD with TNF- $a$ treatment promoted Sirt1 translocation from nuclei to cytoplasm in rheumatoid FLSs, Sirt1 immunofluorescence was performed with sections of paraffin-embedded interphalangeal joints from $\mathrm{CIA}$ mice or MH7A cells. Sirt1 expression in nuclear or cytoplasm fractions of MH7A cells was detected by western blots.

Compared with WT CIA mice, the percentage of Sirt1-positive nuclei relative to 4', 6-diamidino-2-phenylindole (DAPI) nuclei of synovial cells increased in vehicle-treated $C Y P 27 B 1^{-1}$ CIA mice. Compared with vehicle-treated $C Y P 27 B 1^{-1}$ CIA mice, the percentage of Sirt1-positive nuclei relative to DAPI nuclei of synovial cells decreased in VD-treated CYP27B1 ${ }^{-/}$CIA mice (Figures $7 a$ and $b$ ).

Compared with the serum-free control group, the percentage of Sirt1-positive nuclei relative to DAPI nuclei and Sirt1 protein in the nuclear fraction of MH7A cells increased in the $30 \mathrm{ng} / \mathrm{ml}$ TNF- $a$ treatment group; both parameters significantly decreased with $10^{-7} \mathrm{M}$ VD, or $10^{-7} \mathrm{M}$ VD with $30 \mathrm{ng} / \mathrm{ml} \mathrm{TNF-a}$ treatment. Compared with the $30 \mathrm{ng} / \mathrm{ml}$ TNF- $a$ treatment, the percentage of Sirt1 positive nuclei relative to DAPI nuclei and Sirt1 protein in the nuclear fraction of $\mathrm{MH} 7 \mathrm{~A}$ cells significantly decreased with $10^{-7} \mathrm{M}$ VD, or $10^{-7} \mathrm{M}$ VD with $30 \mathrm{ng} / \mathrm{ml}$ TNF- $a$ treatments. Compared with the $10^{-7} \mathrm{M}$ VD-treatment group, the percentage of Sirt1-positive nuclei relative to DAPI nuclei and Sirt1 protein in the nuclear fraction of MH7A cells decreased with $10^{-7} \mathrm{M}$ VD with $30 \mathrm{ng} / \mathrm{ml}$ TNF- $a$ treatment (Figures 7c-f).

Compared with the serum-free control group, Sirt1 protein in the cytoplasmic fraction of $\mathrm{MH} 7 \mathrm{~A}$ cells decreased in the $30 \mathrm{ng} /$ $\mathrm{ml} \mathrm{TNF-a-treatment} \mathrm{group;} \mathrm{it} \mathrm{significantly} \mathrm{increased} \mathrm{with} 10^{-7}$ $\mathrm{M}$ VD, or $10^{-7} \mathrm{M}$ VD with $30 \mathrm{ng} / \mathrm{ml}$ TNF- $a$ treatment. Compared with the group treated with $30 \mathrm{ng} / \mathrm{ml}$ TNF- $a$, Sirt1 protein in the cytoplasmic fraction of MH7A cells significantly increased with groups treated with $10^{-7} \mathrm{M}$ VD, and $10^{-7} \mathrm{M}$ VD with $30 \mathrm{ng} / \mathrm{ml}$ TNF- $a$. Compared with the $10^{-7} \mathrm{M}$ VD treatment group, Sirt1 protein in the cytoplasmic fraction of MH7A cells increased in the group of $10^{-7} \mathrm{M} V D$ and $30 \mathrm{ng} / \mathrm{ml}$ TNF- $a$ treatments (Figures 7c-f).

These results demonstrated that VD with TNF- $a$ promoted Sirt1 translocation from the nucleus to the cytoplasm in rheumatoid FLSs more than VD alone, and reversed the inhibitory effect of TNF- $a$ on Sirt1 translocation from the nucleus to the cytoplasm.

Apoptosis of normal FLSs were not induced by VD with TNF- $\boldsymbol{a}$. To determine whether apoptosis of normal FLSs was induced by VD with TNF- $a$, normal FLSs were treated with the same treatment as MH7A cells. The percentages of AV-positive and $\mathrm{Pl}$-negative $(\mathrm{AV}+\mathrm{PI}-), \mathrm{AV}$ and $\mathrm{PI}$ doublepositive $(\mathrm{AV}+\mathrm{PI}+)$ and total $\mathrm{AV}$-positive $(\mathrm{AV}+)$ normal FLSs in the serum-free control group were $34.87 \pm 1.62 \%$, $6.60 \pm 1.48 \%$ and $41.47 \pm 1.69 \%$, respectively (Supplementary Figures S2A and S2B). However, the percentages of AV $+\mathrm{PI}-, \mathrm{AV}+\mathrm{PI}+$ and total $\mathrm{AV}+\mathrm{FLSs}$ in the serum-free control group of $\mathrm{MH} 7 \mathrm{~A}$ cells were $5.99 \pm 0.65 \%, 3.66 \pm 0.47 \%$ and $9.65 \pm 0.73 \%$ respectively (Figures $4 a$ and $b$ ). These results demonstrated that the resistance of normal FLSs to serumfree culture is poorer than MH7A cells, and easier to be induced into apoptosis. Previous studies support that normal FLSs appear less resistant to apoptosis than RA-FLSs. ${ }^{4}$ Thus, normal FLSs were treated with DMEM or DMEM and $10^{-7} \mathrm{M}$ VD and/or 10 or $30 \mathrm{ng} / \mathrm{ml}$ TNF- $a$ for $24 \mathrm{~h}$. The percentages of $\mathrm{AV}+\mathrm{PI}-, \mathrm{AV}+\mathrm{PI}+$ and total $\mathrm{AV}+\mathrm{FLSs}$ in the serum-free control group of normal FLSs were $5.0 \pm 0.75 \%$, $6.78 \pm 0.71 \%$ and $11.78 \pm 0.25 \%$, respectively (Supplementary Figures S2C and S2D). Compared with the serum-free control group, the percentages of $\mathrm{AV}+\mathrm{PI}-, \mathrm{AV}+\mathrm{PI}+$ or total $\mathrm{AV}+\mathrm{FLSs}$ in the $10^{-7} \mathrm{M}$ VD group, $10 \mathrm{ng} / \mathrm{ml}$ TNF- $a$ group, $10 \mathrm{ng} / \mathrm{ml}$ TNF- $a$ with $10^{-7} \mathrm{M}$ VD group, $30 \mathrm{ng} / \mathrm{ml}$ TNF- $a$ group, and $30 \mathrm{ng} / \mathrm{ml}$ TNF- $a$ with $10^{-7} \mathrm{M}$ VD group were no different (Supplementary Figures S2C and S2D).

\section{Discussion}

In this study, we demonstrated that CYP27B1 deficiency increased cumulative arthritis scores and levels of serous RFs and C-RP. CYP27B1 deficiency exacerbated articular cartilage and bone destruction, joint space narrowing, joint stiffness, deformity and dysfunction, synovitis and TNF- $a$ 
secretion. CYP27B1 deficiency caused FLSs hyperplasia with increased proliferation and decreased apoptosis in CIA mice. These typical RA phenotypes in CYP27B1 deficiency were largely rescued by VD treatment. In vitro, results demonstrated that VD with TNF- $a$ treatment upregulated p53 acetylationmediated apoptosis in human rheumatoid FLS-MH7A cells by promoting Sirt1 translocation from nuclei to cytoplasm. These findings indicated that VD with TNF-a protected against RA by a
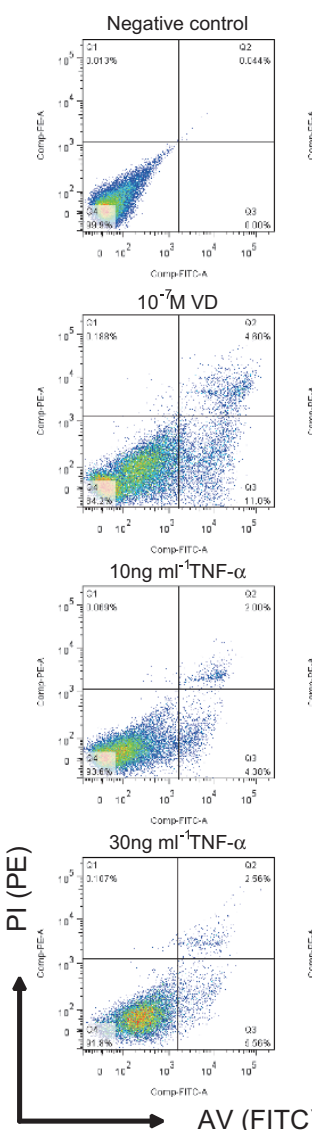

AV (FITC)
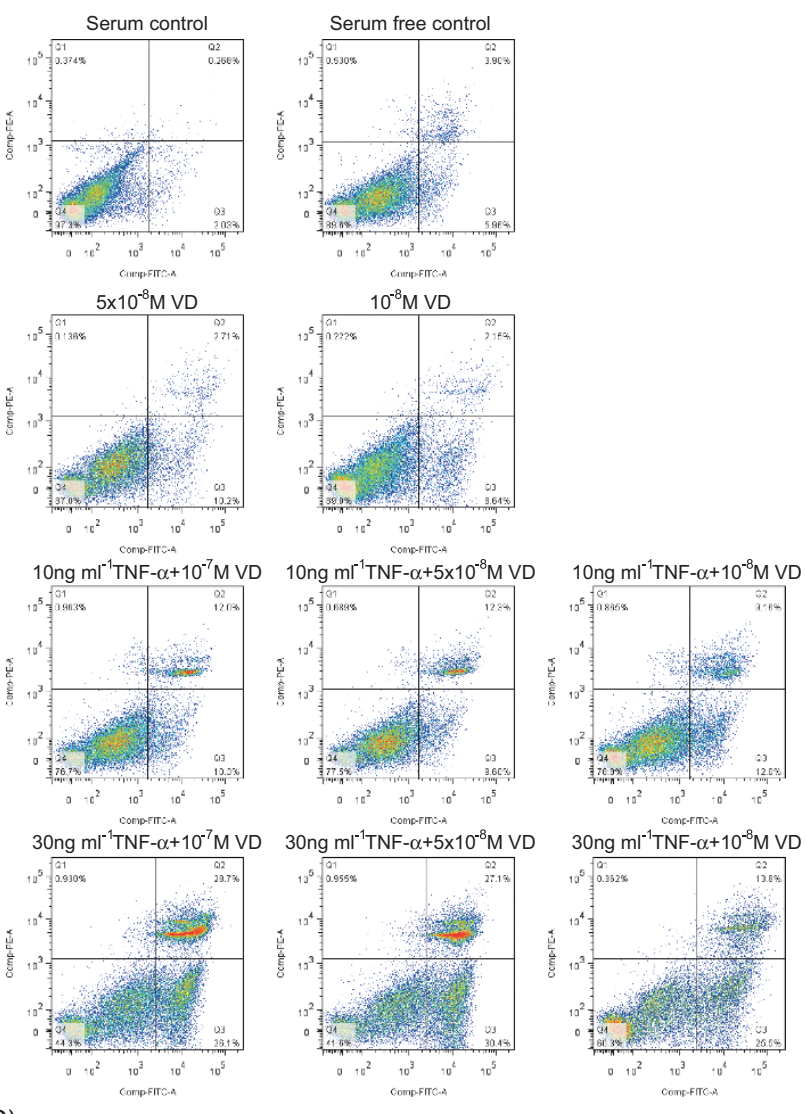

b
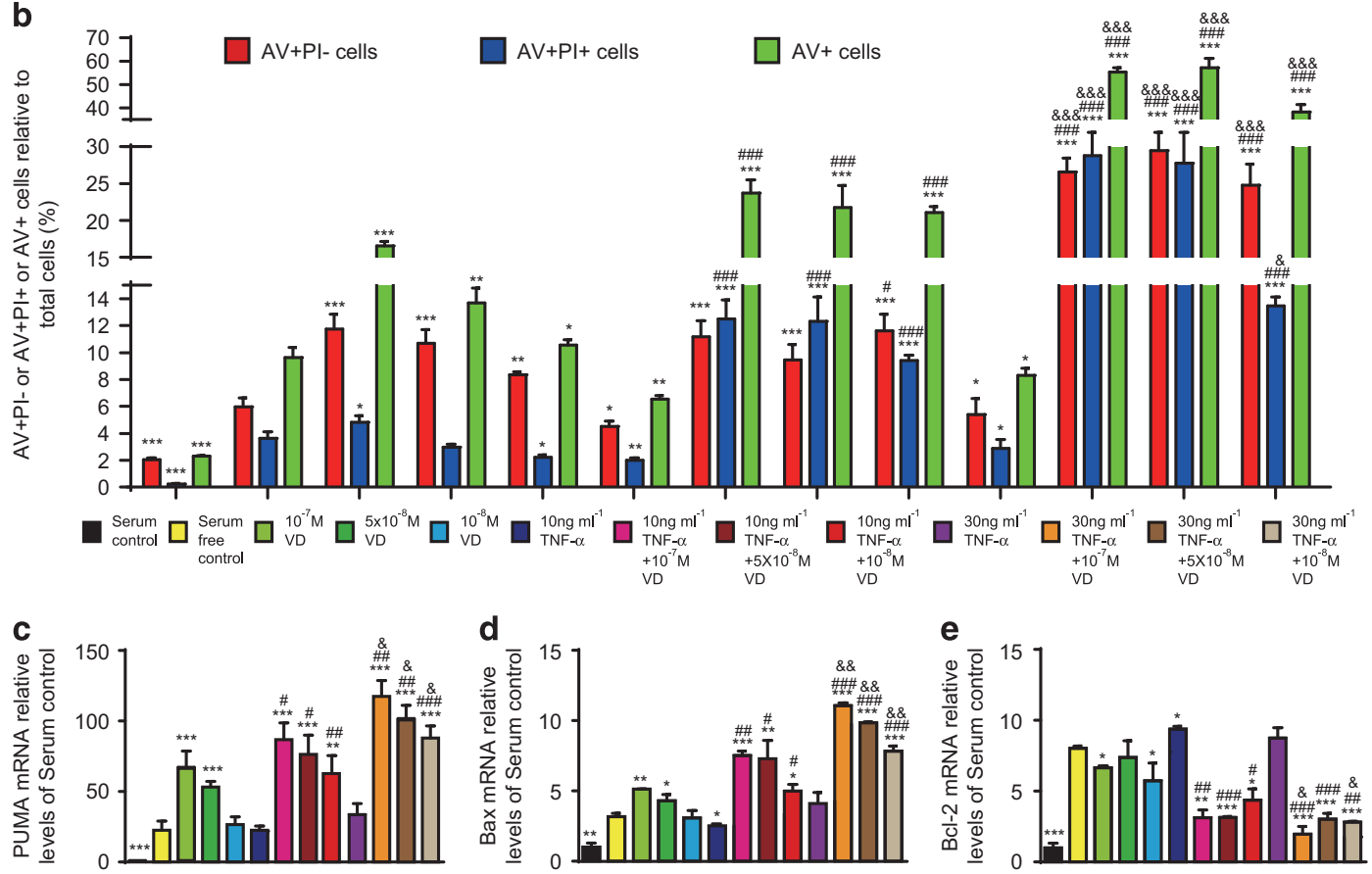

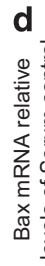

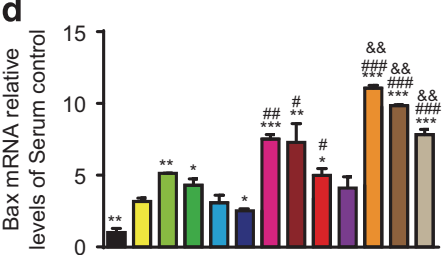

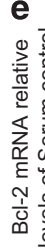

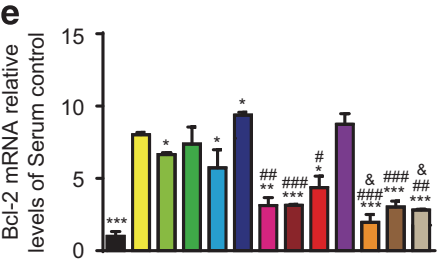


promoting p53 acetylation-mediated apoptosis via Sirt1 translocation from nuclei to cytoplasm in RA-FLSs.

Previous studies suggest that FLS hyperplasia is a key to both initiation and the perpetuation of RA. FLS hyperplasia has been linked most prominently to the progressive destruction of articular structures, particularly cartilage. ${ }^{7,17}$ The ability of hyperplastic FLSs to erode articular cartilage is a multistep process that includes attachment to cartilage and synthesis of proteolytic enzymes that degrade the extracellular matrix. ${ }^{4} \mathrm{~A}$ broad array of inflammatory mediators and cytokines are secreted by hyperplastic FLSs to induce apoptosis of articular cartilage. ${ }^{4}$ Hyperplastic FLS results in joint stiffness, deformity and dysfunction. ${ }^{4}$ Therefore, inhibiting inflammation and proliferation and promoting apoptosis of FLS is critical for RA treatment.

Previous observations demonstrate that TNF- $\alpha$ induces proinflammatory responses and upregulates TNF- $a$ and IL- $1 \beta$ through activating the NF- $k \mathrm{~B}$ signaling pathway that stimulates FLS overgrowth to form a mass of synovial tissue. ${ }^{11,16,18}$ Our results revealed that $C Y P 27 B 1$ deficiency upregulated expression of TNF- $a$ and IL- $1 \beta$, increased CD3-positive and F4/80-positive inflammatory cells and PCNA-positive FLSs. We found that VD downregulated expression of TNF- $a$ and $\mathrm{IL}-1 \beta$, and decreased CD3-positive and F4/80-positive inflammatory cells and PCNA-positive FLSs in CYP27B1-deficient $\mathrm{CIA}$ mice. Results from a previous study support that NF- $\kappa \mathrm{B}-$ mediated pro-inflammatory gene transcription is repressed by VD, resulting in suppressed production of inflammatory cytokines such as IL-1 $\beta$ and TNF- $a .^{13}$ Our study further demonstrated that VD and TNF- $a$ treatment significantly inhibited NF-kB-p65 expression in human rheumatoid FLSs. Thus, VD could be used for RA treatment as an antiinflammatory and anti-proliferative molecule for hyperplastic FLSs.

Several lines of evidence suggest that impaired and inhibited apoptosis contributes to the accumulation of RAFLSs, and is pivotal to RA-FLS-mediated disease progression. ${ }^{17}$ Therefore, finding pro-apoptotic molecules of hyperplastic FLSs is important for RA treatment. Our results revealed that CYP27B1 deficiency decreased Caspase3positive and TUNEL-positive FLSs. We also found that VD increased the percentages of Caspase3-positive and TUNELpositive FLSs in CYP27B1-deficient CIA mice compared to WT CIA mice. The percentage of TNF- $a$-positive cells in synovial membranes increased in VD-treated CYP27B1deficient CIA mice compared to WT CIA mice. Consistent with these results, VD might cooperate with TNF- $a$ to promote apoptosis of RA-FLSs in vivo. Consistently, VD with TNF-a treatment significantly increased $\mathrm{AV}+\mathrm{PI}-, \mathrm{AV}+\mathrm{PI}+$ and $\mathrm{AV}$ +cells and Caspase 3 protein in human rheumatoid FLSs in vitro. Thus, VD could also be a pro-apoptotic molecule in hyperplastic FLSs, in cooperation with TNF-a, to promote apoptosis for RA treatment.

As a critical tumor suppressor gene and apoptotic regulator implicated in RA, p53 induces cell apoptosis through posttranslational modification to upregulate downstream proapoptotic genes Bax, PUMA and Noxa. P53 also combines with the anti-apoptotic gene $\mathrm{Bcl}-2$ to inhibit anti-apoptotic effects. ${ }^{4,19}$ Loss or inactivation of p53 caused by functional mutations has been universally demonstrated in RA-FLSs, most extensively in patients with advanced, destructive disease. ${ }^{4,20,21}$ P53 mutations increase apoptosis resistance and the level of inflammatory secretion in RA-FLSs. ${ }^{4,21} \mathrm{We}$ found that VD with TNF- $a$ treatment increased Bax and PUMA and decreased $\mathrm{Bcl}-2 \mathrm{mRNA}$ and protein in human rheumatoid FLSs. Moreover, PFT- $a$, a p53 pro-apoptotic inhibitor, decreased apoptosis of human rheumatoid FLSs induced by VD and TNF- $a$. Our results demonstrated that VD with TNF- $a$ promoted apoptosis of human rheumatoid FLSs through upregulating p53 pro-apoptotic signaling and ameliorated the development of RA. Recent evidence suggests that PUMA induces apoptosis not only through a p53-dependent mechanism, but also through p53-independent signaling. ${ }^{4,22}$ Consistently, our results suggested that PUMA was still expressed, even if PFT- $a$ was supplied to inhibit p53 apoptotic signaling in human rheumatoid FLSs. Therefore, apoptosis of RA-FLSs induced by VD and TNF- $a$ supplement might be partly mediated by p53-independent pro-apoptotic signaling; this hypothesis remains to be investigated.

P53 acetylation is a post-translational modification that enhances the ability of p53 to regulate downstream genes. ${ }^{23}$ Equilibrium of p53 acetylation is partly maintained by Sirt1. Sirt1 preferentially de-acetylates p53 at K382 to have a profound negative impact on the capacity of p53 to induce expression of target genes involved in apoptosis such as PUMA and Bax. ${ }^{19}$ The p53 de-acetylation caused by Sirt1 inhibits p53-dependent pro-apoptosis by increasing ubiquitination-mediated degradation of p53., 4 Evidence suggests that Sirt1 is highly expressed in RA-FLSs, which is positively related to RA severity. ${ }^{24,25}$ Our study found that VD with TNF- $a$ inhibited p53 de-acetylation, increased p53 acetylation and promoted p53-dependent pro-apoptosis.

$N F-k B$ is constitutively activated in $R A .^{26}$ The antiapoptogenic function of NF- $k \mathrm{~B}$ is well recognized, and is achieved through the gene expression of several antiapoptogenic molecules, including $B c l-x L, X I A P, C l A P 1$, CIAP2 and TRAFs induced by NF- $\mathrm{BB}$. ${ }^{6}$ Previous studies have reported that NF- $K B-p 65$ phosphorylation at Ser-536 contributes to the inhibition of p53 transcriptional activity and subsequent anti-apoptotic effects. ${ }^{27,28}$ Our results demonstrated that VD with TNF- $a$ treatment significantly

Figure 4 VD with TNF- $\alpha$ promoted apoptosis of rheumatoid FLSs. Human rheumatoid FLS-MH7A cells were treated with DMEM and 10\% FBS (serum control), DMEM (serum-free control), DMEM and indicated concentrations of VD with or without TNF- $\alpha$. (a) Flow cytometry of double-stained cells using annexin V (AV) and propidium iodide (PI). (b) AV-positive but PI-negative cells ( $\mathrm{AV}+\mathrm{PI}-), \mathrm{AV}$ and PI double-positive cells $(\mathrm{AV}+\mathrm{PI}+)$, and total AV-positive cells $(\mathrm{AV}+)$ were quantified. Values are mean $\pm \mathrm{S}$.E.M. of six determinations per group. ${ }^{\star} P<0.05 ;{ }^{* *} P<0.01 ;{ }^{* \star} P<0.001$ compared to serum-free control. ${ }^{\#} P<0.05$; ${ }^{\# \#} P<0.001$ compared with the same concentration of VD. ${ }^{\&} P<0.05$;

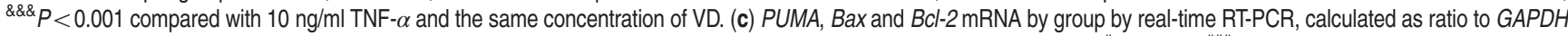
mRNA, expressed relative to serum control. ${ }^{\star} P<0.05$; ${ }^{\star \star} P<0.01$; ${ }^{* \star *} P<0.001$ compared with serum-free control. ${ }^{\#} P<0.05$; \#\#\# $P<0.001$ compared with the same concentration of VD. ${ }^{\&} P<0.05$; ${ }^{\text {\&\& }} P<0.001$ compared with $10 \mathrm{ng} / \mathrm{ml}$ TNF- $\alpha$ and the same concentration of VD 
Table 2 VD with TNF- $a$ induced apoptosis of rheumatoid FLSs through VDR and p53 pro-apoptotic signaling

\begin{tabular}{|c|c|c|c|c|c|c|}
\hline & $\begin{array}{c}\mathrm{AV}+\mathrm{PI}- \\
\text { cells }\end{array}$ & $\begin{array}{c}\mathrm{AV}+\mathrm{PI}+ \\
\text { cells }\end{array}$ & $\mathrm{AV}+$ cells & $\begin{array}{c}P U M A \\
\text { mRNA } \\
\text { levels }\end{array}$ & $\begin{array}{c}\text { Bax } \\
\text { mRNA } \\
\text { levels }\end{array}$ & $\begin{array}{c}B c l-2 \\
\text { mRNA } \\
\text { levels }\end{array}$ \\
\hline $\begin{array}{l}\text { Serum } \\
\text { control }\end{array}$ & $\downarrow \downarrow \downarrow$ & $\downarrow \downarrow \downarrow$ & $\downarrow \downarrow \downarrow$ & $\downarrow \downarrow \downarrow$ & $\downarrow \downarrow \downarrow$ & $\downarrow \downarrow \downarrow$ \\
\hline $\begin{array}{l}\text { Serum free } \\
\text { control }\end{array}$ & & & & & & \\
\hline $\begin{array}{l}10^{-7} \mathrm{M} \\
\text { VD+NC } \\
\text { siRNA }\end{array}$ & $\uparrow \uparrow \uparrow$ & 一 & $\uparrow \uparrow \uparrow$ & $\uparrow \uparrow \uparrow$ & $\uparrow \uparrow$ & $\downarrow \downarrow$ \\
\hline $10^{-7} \mathrm{M}$ & - & - & - & - & - & - \\
\hline $\begin{array}{l}\text { VD+VDR } \\
\text { siRNA }\end{array}$ & $\downarrow \downarrow$ & $\downarrow$ & $\downarrow \downarrow$ & $\downarrow \downarrow$ & $\downarrow \downarrow$ & $\uparrow$ \\
\hline $10^{-7} \mathrm{M}$ & $\downarrow \downarrow$ & $\downarrow$ & $\downarrow \downarrow$ & $\downarrow$ & $\downarrow$ & 一 \\
\hline $\mathrm{VD}+30 \mu \mathrm{M}$ & $\downarrow \downarrow \downarrow$ & $\downarrow$ & $\downarrow \downarrow \downarrow$ & $\downarrow \downarrow \downarrow$ & $\downarrow \downarrow \downarrow$ & $\uparrow \uparrow$ \\
\hline PFT- $\alpha$ & $\downarrow$ & $\downarrow$ & $\downarrow$ & $\downarrow$ & $\downarrow$ & $\uparrow$ \\
\hline $\begin{array}{l}\text { 30ng ml } \\
\text { TNF- } \alpha+\mathrm{NC} \\
\text { siRNA }\end{array}$ & - & $\downarrow$ & $\downarrow$ & - & - & - \\
\hline $\begin{array}{l}\text { 30ng ml } \\
\text { TNF- } \alpha+ \\
10^{-7} \mathrm{M} \\
\text { VD+NC } \\
\text { siRNA }\end{array}$ & $\begin{array}{l}\uparrow \uparrow \uparrow \\
\uparrow \uparrow \uparrow\end{array}$ & $\begin{array}{l}\uparrow \uparrow \uparrow \\
\uparrow \uparrow \uparrow\end{array}$ & $\begin{array}{l}\uparrow \uparrow \uparrow \\
\uparrow \uparrow \uparrow\end{array}$ & $\begin{array}{c}\uparrow \uparrow \uparrow \\
\uparrow \uparrow\end{array}$ & $\begin{array}{l}\uparrow \uparrow \uparrow \\
\uparrow \uparrow \uparrow\end{array}$ & $\begin{array}{l}\downarrow \downarrow \downarrow \\
\downarrow \downarrow \downarrow\end{array}$ \\
\hline $30 \mathrm{ng} \mathrm{ml}^{-1}$ & $\uparrow \uparrow \uparrow$ & $\uparrow \uparrow \uparrow$ & $\uparrow \uparrow \uparrow$ & $\uparrow \uparrow \uparrow$ & $\uparrow \uparrow$ & $\downarrow \downarrow$ \\
\hline $\begin{array}{l}\text { TNF- } \alpha+ \\
10^{-7} \mathrm{M} \\
\text { VD+VDR } \\
\text { siRNA }\end{array}$ & $\frac{\uparrow \uparrow \uparrow}{-}$ & $\begin{array}{l}\uparrow \uparrow \uparrow \\
\downarrow \downarrow \downarrow\end{array}$ & $\begin{array}{c}\uparrow \uparrow \uparrow \\
\downarrow\end{array}$ & $\begin{array}{c}\uparrow \uparrow \\
\downarrow\end{array}$ & $\begin{array}{c}\uparrow \uparrow \uparrow \\
\downarrow\end{array}$ & $\begin{array}{c}\downarrow \downarrow \\
\uparrow\end{array}$ \\
\hline $30 \mathrm{ng} \mathrm{ml}^{-1}$ & $\uparrow \uparrow \uparrow$ & - & $\uparrow \uparrow \uparrow$ & $\uparrow \uparrow$ & $\uparrow$ & $\downarrow$ \\
\hline TNF- $\alpha+$ & $\uparrow \uparrow \uparrow$ & $\uparrow$ & $\uparrow \uparrow \uparrow$ & $\uparrow \uparrow$ & $\uparrow \uparrow \uparrow$ & $\downarrow$ \\
\hline $10^{-7} \mathrm{M}$ & $\downarrow \downarrow \downarrow$ & $\downarrow \downarrow \downarrow$ & $\downarrow \downarrow \downarrow$ & $\downarrow \downarrow$ & $\downarrow \downarrow \downarrow$ & $\uparrow \uparrow$ \\
\hline $\begin{array}{l}\text { VD }+30 \mu \mathrm{M} \\
\text { PFT- } \alpha\end{array}$ & $\downarrow \downarrow \downarrow$ & $\downarrow \downarrow \downarrow$ & $\downarrow \downarrow \downarrow$ & $\downarrow$ & $\downarrow$ & $\uparrow$ \\
\hline
\end{tabular}

Values are mean \pm SEM of six determinations per group. —: No difference; $\uparrow$ or $\downarrow$ : $\mathrm{P}<$ 0.05 ; $\uparrow$ or $\downarrow \downarrow$ : $\mathrm{P}<0.01$; $\uparrow \uparrow$ or $\downarrow \downarrow \downarrow: \mathrm{P}<0.001$ compared with serum-free control. $\uparrow$ or $\downarrow: \mathrm{P}<0.05$; $\uparrow$ or $\downarrow \downarrow: \mathrm{P}<0.01$; $\uparrow \uparrow \uparrow$ or $\downarrow \downarrow \downarrow: \mathrm{P}<0.001$ compared with compared with $10^{-7} \mathrm{M}$ VD but not the TNF- $\alpha$-treated group. —: No difference; $\uparrow$ or $\downarrow: \mathrm{P}<0.05$; $\uparrow$ or $\downarrow \downarrow: \mathrm{P}<0.01 ; \downarrow \downarrow \downarrow: \mathrm{P}<0.001$ compared with $10^{-7} \mathrm{M}$ VD and NC siRNA with or without $30 \mathrm{ng} \mathrm{ml}^{-1} \mathrm{TNF}-\alpha . \uparrow$ or $\downarrow$ : $\mathrm{P}<0.05$; $\downarrow \downarrow \downarrow$ : $\mathrm{P}<0.001$ compared with $10^{-7} \mathrm{M}$ VD and VDR siRNA with or without $30 \mathrm{ng} \mathrm{ml}^{-1} \mathrm{TNF}-\alpha$. 
decreased expression of NF-kB-p65 and NF-kB-p65 (phospho S536) and induced a p53-mediated pro-apoptotic effect in RA-FLSs.
Whether Sirt1 acted to mediate anti-apoptosis or proapoptosis pathogenic responses in RA-FLSs is uncertain. Previous studies demonstrated that Sirt1 overexpression a
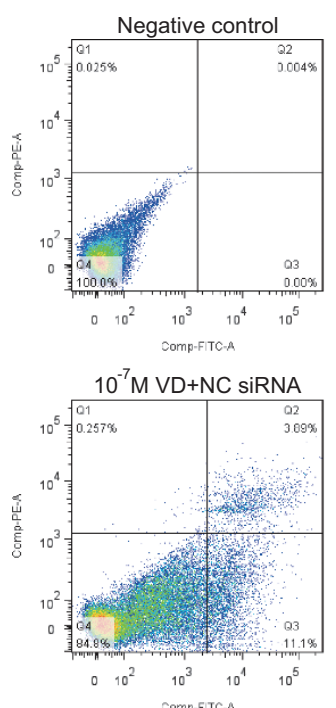

Ong $\mathrm{ml}^{-1} \mathrm{TNF}-\alpha+\mathrm{NC}$ siRNA

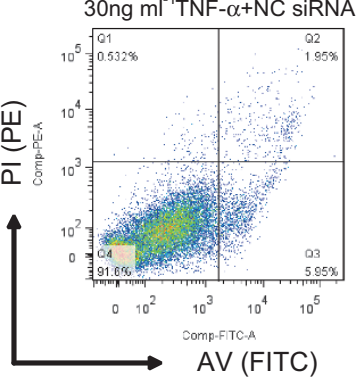

b

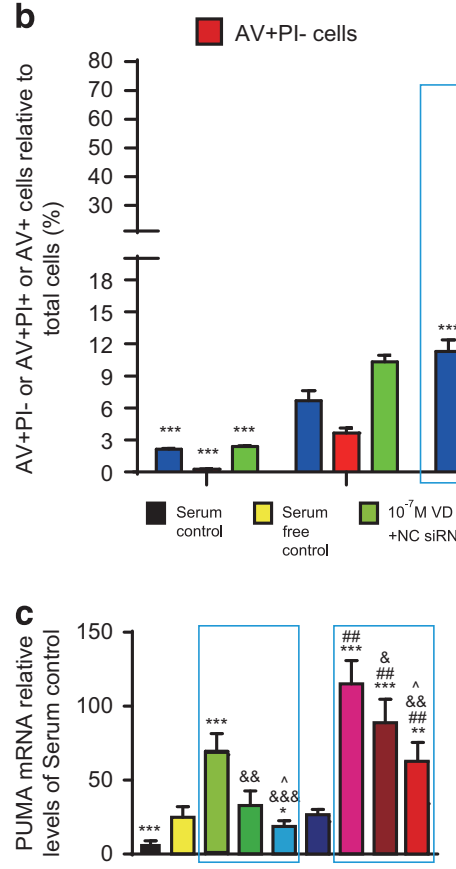

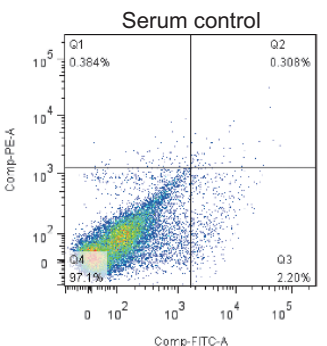
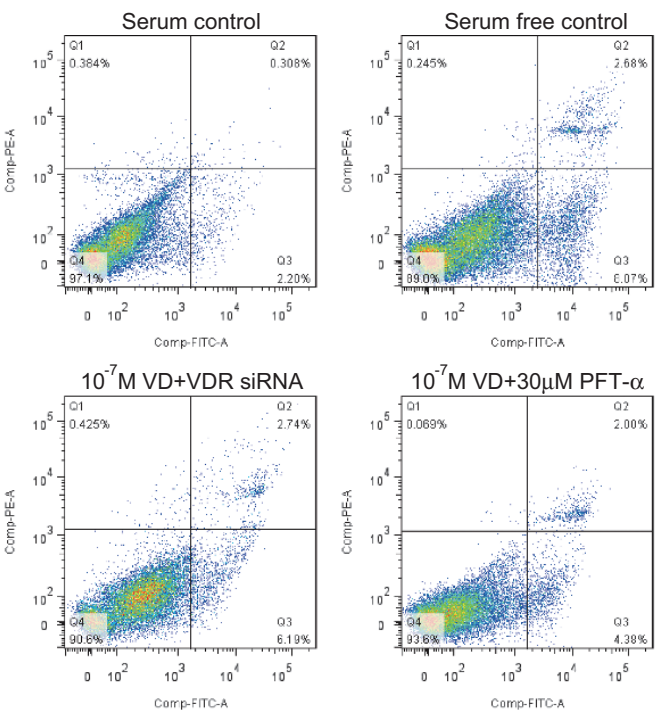

30ng $\mathrm{ml}^{-1} \mathrm{TNF}-\alpha+10^{-7} \mathrm{M}$ VD + NC SiRNA

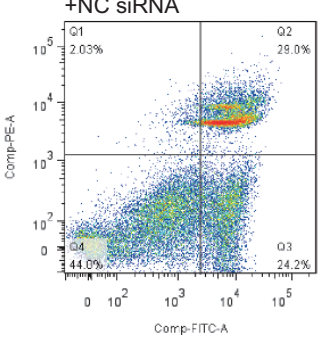

$\mathrm{AV}+\mathrm{PI}+$ cells

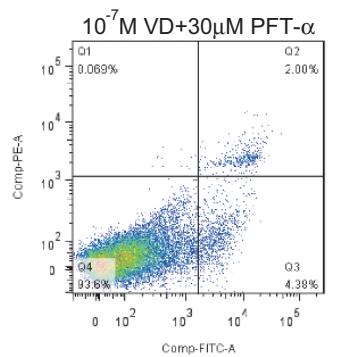

30ng $\mathrm{ml}^{-1} \mathrm{TNF}-\alpha+10^{-7} \mathrm{M}$ VD

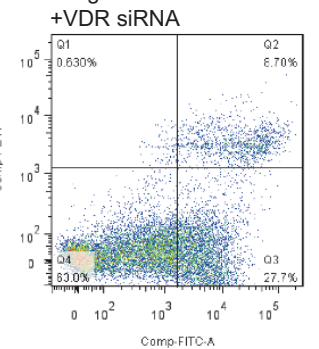

$\mathrm{AV}+$ cells

30ng $\mathrm{ml}^{-1} \mathrm{TNF}-\alpha+10^{-7} \mathrm{M}$ VD+ $30 \mu \mathrm{M}$ PFT- $\alpha$
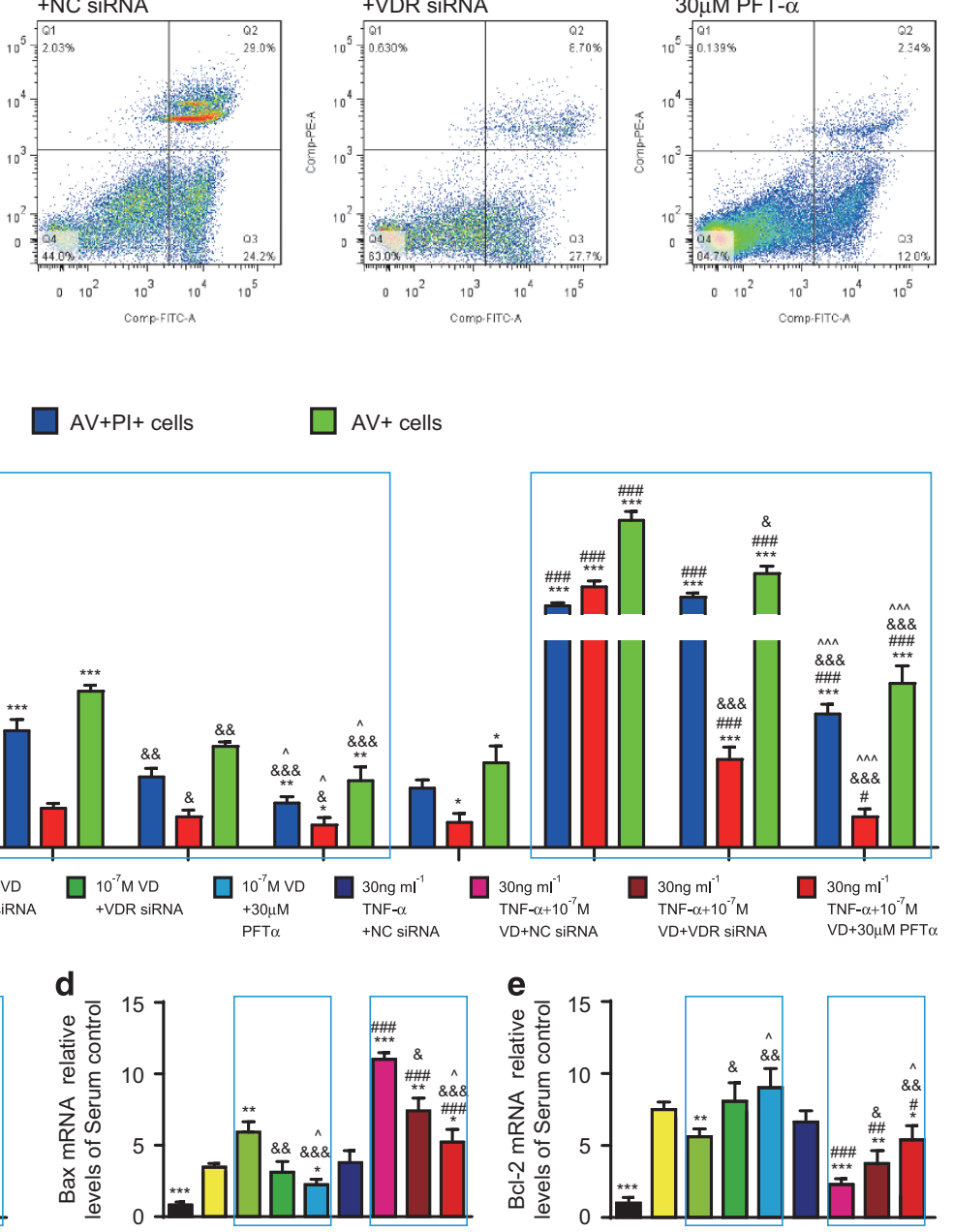

Figure 5 For caption please refer page 12. 
promoted apoptotic resistance and inflammatory secretion in RA-FLSs; ${ }^{25}$ Sirt1 gene silencing promotes apoptosis of RAFLSs. ${ }^{29}$ In contrast, evidence suggests that Sirt1 is important in anti-inflammation through downregulating expression of the cysteine-rich protein 61 in RA-FLSs; ${ }^{30}$ resveratrol, a Sirt1 activator, induces apoptosis of RA-FLSs. ${ }^{31}$ Recent studies report that subcellular localization of Sirt1 is associated with cell fate. Nuclear-localized Sirt1 is involved in anti-apoptosis, whereas cytoplasmically localized Sirt1 promote apoptosis that is independent of de-acetylation but dependent on Caspase signaling. ${ }^{32,33}$ Moreover, overexpression and nuclear-localization of Sirt1 significantly promotes apoptotic resistance in RA-FLSs. ${ }^{25}$ Thus, the subcellular localization of Sirt1 in FLSs may be pivotal to RA progression. Our results demonstrated that TNF- $a$ treatment inhibited translocation of Sirt1 from nuclei to cytoplasm; VD with TNF- $a$ treatments promoted Sirt1 translocation from nuclei to cytoplasm in human rheumatoid FLSs. However, further investigation is needed to determine if cytoplasm-localized Sirt1 is necessarily associated with pro-apoptosis in RA-FLSs and the exact regulating mechanism.

In conclusion, the 'in vivo' and 'in vitro' data presented in this paper strongly suggest that VD with TNF-a protected against RA by promoting apoptosis of RA-FLSs. Our findings implied that clinical administration of VD could be as a specific therapy to prevent RA progression.

\section{Materials and Methods}

Mice and genotyping. Adult CYP27B1 heterozygote $\left(C Y P 27 B 1^{+/-}\right)$mice (129sv/J hybrid background) were backcrossed 10-12 times to the BALB/C background and mated to generate CYP27B1 homozygotes $\left(C Y P 27 B 1^{--}\right)$and their wild-type (WT) littermates. Mice were genotyped by PCR as described previously. ${ }^{34,35}$ Male $\mathrm{CYP}^{27 B 1^{--}}$and WT mice were used at 10 weeks of age. Mice were weaned at 3 weeks and fed rescue diet (TD96348 Teklad, Madison, WI, USA) containing $2 \%$ calcium, $1.25 \%$ phosphorus and $20 \%$ lactose until they were 19 weeks old. We confirmed that serum calcium and phosphorus levels were normalized in $\mathrm{CYP}_{2} \mathrm{BB} 1^{-1}$ mice and WT littermates fed with rescue diet (Supplementary Table S1).

This study was carried out in strict accordance with the guidelines of the Institute for Laboratory Animal Research of Nanjing Medical University in Nanjing, China. The protocol was approved by the Committee on the Ethics of Animal Experiments of Nanjing Medical University (Approval ID 20111201).

Administration of VD in vivo. The 10-week-old mice were divided into three

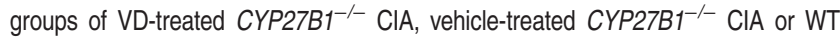
CIA mice. For 9 weeks, animals received intraperitoneal treatment of vehicle or $1 \mu \mathrm{g} / \mathrm{kg}$ VD (Sigma-Aldrich, St. Louis, MO, USA) every other day.
The 10-week-old male WT mice derived from BALB/c background were divided into two groups of VD-treated and vehicle-treated mice. For 3 weeks, animals received intraperitoneal treatment of vehicle or $1 \mu \mathrm{g} / \mathrm{kg}$ VD every other day.

Measurements of serum calcium, phosphorus and VD. Mice were anesthetized with $3 \%$ pentobarbital sodium $(40 \mathrm{mg} / \mathrm{kg}$ ) and the abdomen depilated. Blood was taken by suction from the heart with a $1 \mathrm{ml}$ syringe.

Serum calcium and phosphorus levels were analyzed by an autoanalyzer (Beckman Synchron67; Beckman Instruments, Fullerton, CA, USA) from 10-week-old CYP27B1 ${ }^{-/-}$mice and WT littermates.

Serum VD was measured by radioimmunoassay (Diagnostic Products, Los Angeles, CA, USA) from 10-week-old CYP27B1 $1^{-1}$ mice and WT littermates, 19week-old VD-treated $C Y P 27 B 1^{-/}$, vehicle-treated $C Y P 27 B 1^{-/-}$and WT CIA mice, and 13-week-old VD-treated and vehicle-treated WT mice.

Induction and assessment of collagen-induced arthritis. CIA was induced as previously described. ${ }^{9,14,36}$ Immunization-grade chicken type II collagen (Chondrex Inc., Redmond, WA, USA) was dissolved in $0.1 \mathrm{mM}$ acetic acid (2 mg/ml) at $4{ }^{\circ} \mathrm{C}$ overnight and emulsified with an equal volume of complete Freund's adjuvant ((Sigma-Aldrich) on ice. Male CYP27B1 $1^{-1}$ and WT littermates at 10 weeks of age were injected subcutaneously at the tail base with $100 \mu \mathrm{l}$ emulsion, which was considered the primary immunization on Day 1 . Secondary immunization on Day 22 was similar to primary immunization on Day 22. Mice were analyzed by three independent, blinded examiners every sixth day from Day 7 and monitored for signs of arthritis onset using clinical parameters of cumulative arthritis scores for subjective evaluation of arthritis severity. Clinical arthritis was scored as previously described: ${ }^{9}$ 0 , no evidence of erythema and swelling; 1 , erythema and mild swelling confined to the tarsals or ankle joint; 2, erythema and mild swelling extending from the ankle to the tarsals; 3, erythema and moderate swelling extending from the ankle to metatarsal joints; and 4, erythema and severe swelling encompassing the ankle, foot and digits, or ankylosis of the limb. Paw swelling was assessed by measuring the thickness of affected hind paws with $0-10 \mathrm{~mm}$ calipers. ${ }^{36}$

Rheumatoid serum biochemical measurements. At 19 weeks, mice were anesthetized with $3 \%$ pentobarbital sodium $(40 \mathrm{mg} / \mathrm{kg})$ and the abdomen depilated. Blood was taken by suction from the heart with a $1 \mathrm{ml}$ syringe. Serum was isolated for measurements of RFs (E035 RF detection kit) and C-RP (E023 $\mathrm{C}$-RP detection kit) according to the manufacturers' instructions (Nanjing Jiancheng Bioengineering Institute, Nanjing, China).

Histological analysis. Phenotypes of 19-week-old VD-treated CYP27B1 $1^{-/}$ $\mathrm{CIA}$ mice were compared with vehicle-treated $\mathrm{CYP}_{27 B 1^{-1}} \mathrm{CIA}$ and WT CIA mice.

Mice were anesthetized with $3 \%$ pentobarbital sodium $(40 \mathrm{mg} / \mathrm{kg})$ and perfused with $100 \mathrm{ml}$ normal sodium and then fixed with periodate-lysine-paraformaldehyde (PLP) solution. ${ }^{37}$ Hind palms were dissected.

For histochemistry or immunohistochemistry, samples were decalcified and dehydrated in a series of graded ethanol solutions, embedded in paraffin and cut into $5-\mu \mathrm{m}$ sections with rotary microtome (Leica Microsystems Nussloch GmbH, Nubloch, Germany). ${ }^{38}$

Skeletal radiography and micro-computed tomography. Hind palms were removed and dissected free of soft tissue. Contact radiographs were

Figure 5 VD with TNF- $\alpha$ induced apoptosis of rheumatoid FLSs through VDR and p53 pro-apoptotic signaling. Human rheumatoid FLS-MH7A cells were treated with DMEM and $10 \% \mathrm{FBS}$ (serum control), DMEM (serum-free control), DMEM and $10^{-7} \mathrm{M}$ VD and VDR-negative control small interfering RNA (10 $0^{-7} \mathrm{M}$ VD+NC siRNA), DMEM and $10^{-7} \mathrm{M}$ VD and VDR siRNA $\left(10^{-7} \mathrm{M}\right.$ VD+VDR siRNA), DMEM and $10^{-7} \mathrm{M}$ VD and $30 \mu \mathrm{M}$ pifithrin- $\alpha$ (PFT- $\left.\alpha\right)\left(10^{-7} \mathrm{M}\right.$ VD+30 $\mu \mathrm{M}$ PFT- $\left.\alpha\right)$, DMEM and $30 \mathrm{ng} / \mathrm{ml}$ TNF- $\alpha$ and NC siRNA ( $30 \mathrm{ng} / \mathrm{ml}$ TNF- $\alpha+$ NC siRNA), DMEM and $30 \mathrm{ng} / \mathrm{ml} \mathrm{TNF-} \alpha$ and $10^{-7} \mathrm{M}$ VD and NC siRNA (30 ng/ml TNF- $\alpha+10^{-7} \mathrm{M}$ VD+NC siRNA), DMEM and $30 \mathrm{ng} / \mathrm{ml}$ TNF- $\alpha$ and $10^{-7} \mathrm{M}$ VD and $30 \mu \mathrm{M} \mathrm{PFT}-\alpha\left(30 \mathrm{ng} / \mathrm{ml} \mathrm{TNF}-\alpha+10^{-7} \mathrm{M}\right.$ VD $+30 \mu \mathrm{M}$ PFT- $\alpha$ ). (a) Flow cytometry of cells double-stained for annexin V (AV) and propidium iodide (PI). (b) AV-positive but $\mathrm{PI}$-negative cells ( $\mathrm{AV}+\mathrm{PI}-), \mathrm{AV}$ and $\mathrm{PI}$ double-positive cells $(\mathrm{AV}+\mathrm{PI}+)$ and total $\mathrm{AV}$-positive cells $(\mathrm{AV}+)$ were quantified. Values are mean \pm S.E.M. of six determinations per group. ${ }^{\star} P<0.05$; ${ }^{\star *} P<0.01$; ${ }^{* \star} P<0.001$ compared with serum-free control. ${ }^{\#} P<0.05$; \#\#\# $P<0.001$ compared with $10^{-7} \mathrm{M}$ VD but not the TNF- $\alpha$-treated group. ${ }^{\text {\& }} P<0.05$; ${ }^{\text {\& }} P<0.01$; \&\&\& $P<0.001$ compared with $10^{-7} \mathrm{M} V D$ and NC siRNA with or without $30 \mathrm{ng} / \mathrm{ml}$ TNF- $\alpha$ inside the same blue box. $\wedge P<0.05 ; M P<0.001$ compared with $10^{-7} \mathrm{M}$ VD and VDR siRNA with or without $30 \mathrm{ng} / \mathrm{ml}$ TNF- $\alpha$ inside the same blue box. (c) Relative levels of Puma, Bax and Bcl-2 mRNA by group by real-time RT-PCR, calculated as ratio to GAPDH mRNA, expressed relative to serum control. Values are mean \pm S.E.M. of six determinations per group. ${ }^{*} P<0.05 ;{ }^{\star \star} P<0.01 ;{ }^{* \star} P<0.001$ compared with serum-free control. ${ }^{\#} P<0.05$; \#\# $P<0.01$; \#\#\# $P<0.001$ compared with $10^{-7} \mathrm{M}$ VD but not the TNF- $\alpha$-treated group. \& $P<0.05$; \&\& $P<0.01$; \&\& $P<0.001$ compared with $10^{-7} \mathrm{M}$ VD and NC siRNA with or without $30 \mathrm{ng} / \mathrm{ml}$ TNF- $\alpha$ inside the same blue box. $\wedge P<0.05$ compared with $10^{-7} \mathrm{M}$ VD and VDR siRNA with or without $30 \mathrm{ng} / \mathrm{ml}$ TNF- $\alpha$ inside the same blue box 
Table 3 VD with TNF- $a$ promoted p53 acetylation-mediated apoptosis in human rheumatoid FLSs

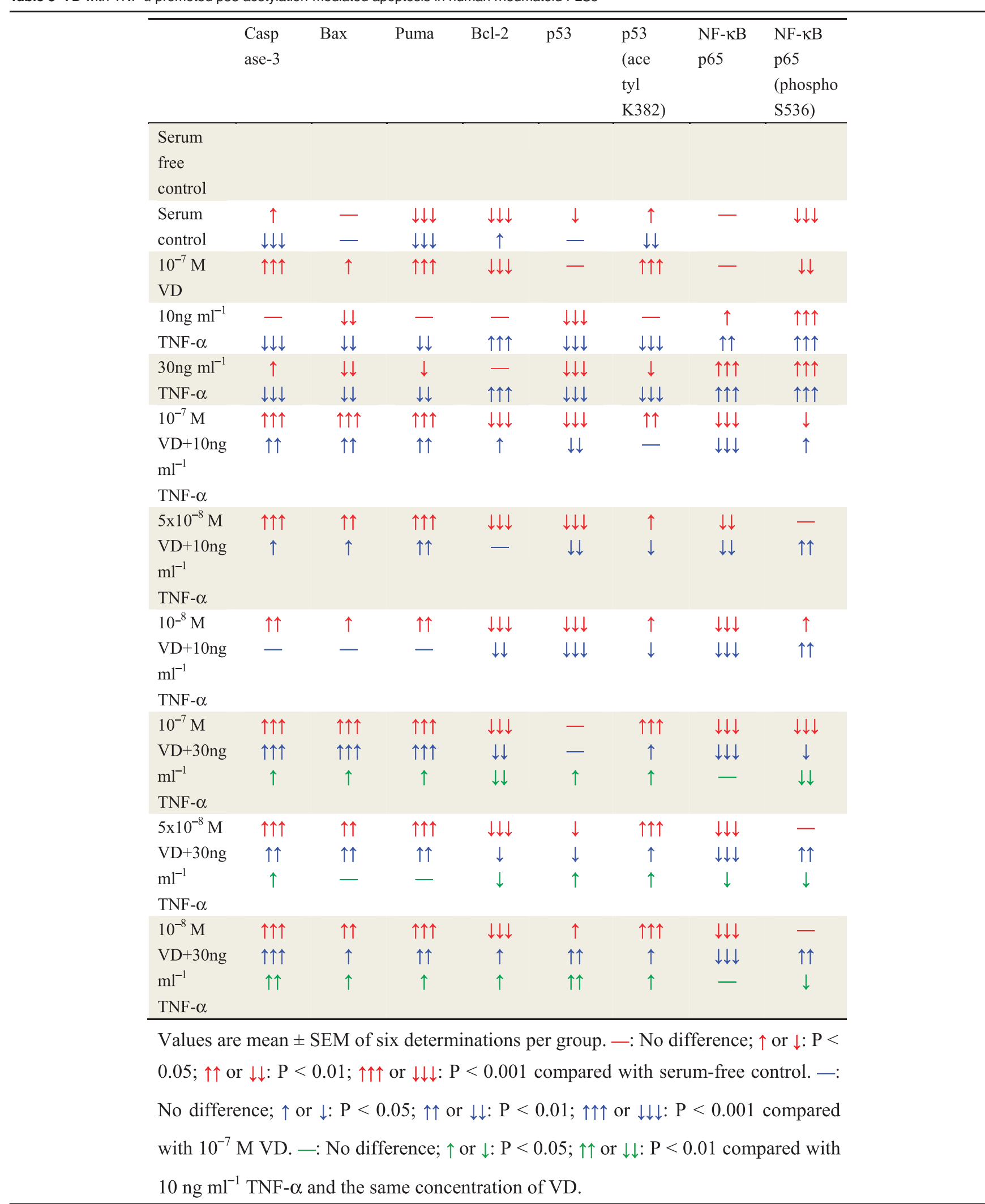



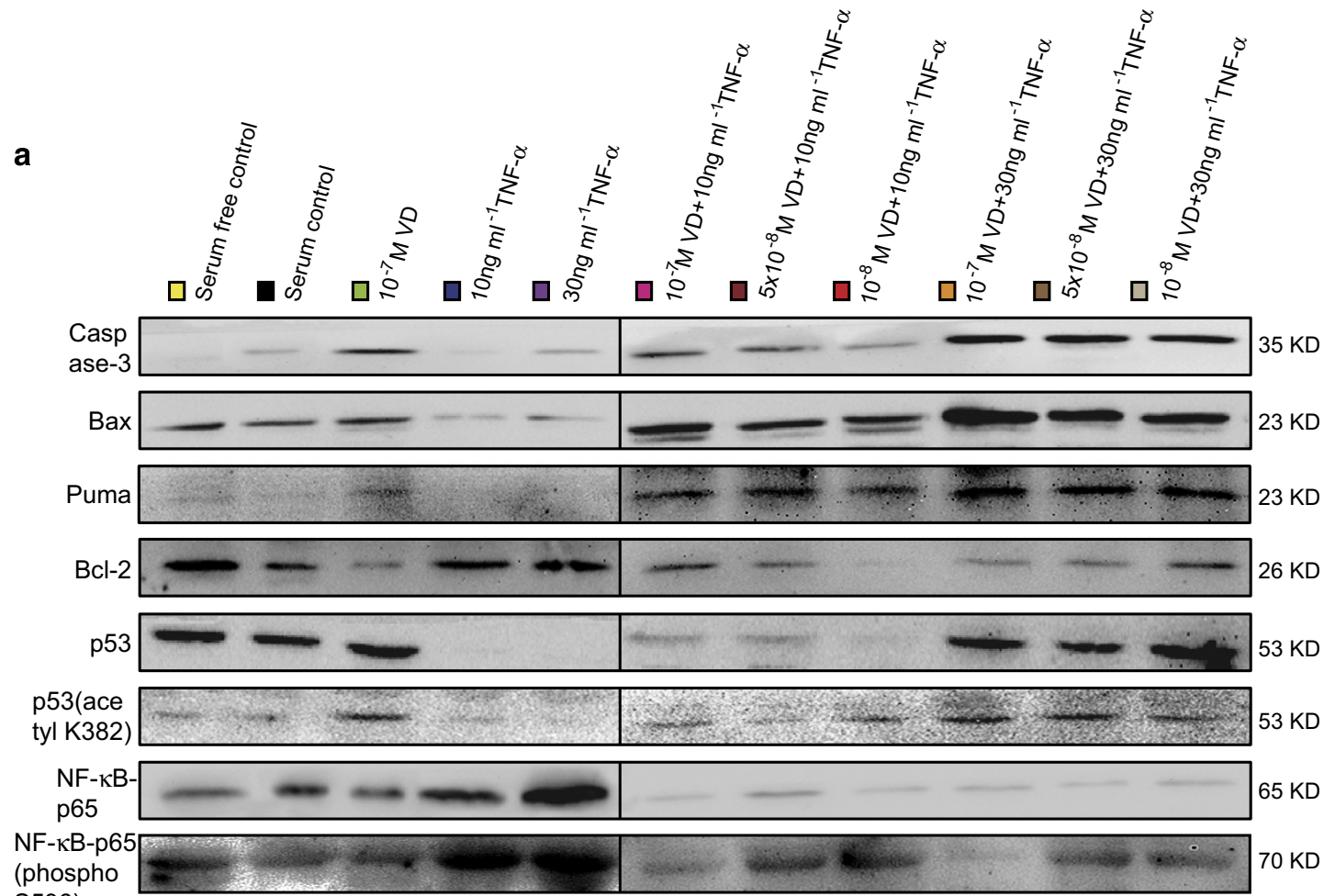
S536)

$\beta$-actin
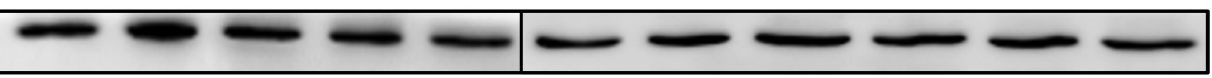

b
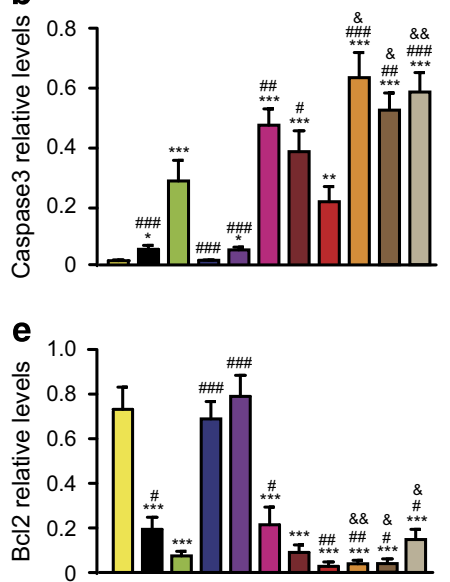

h

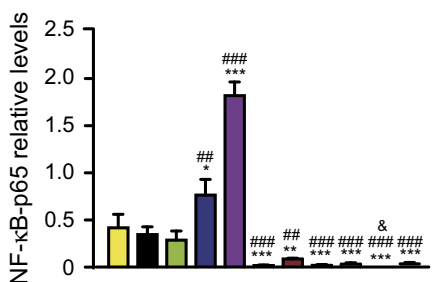

C

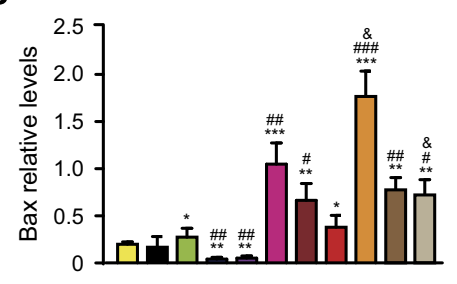

f

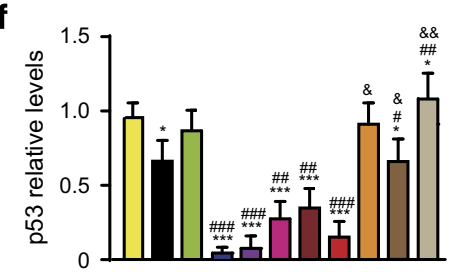

i

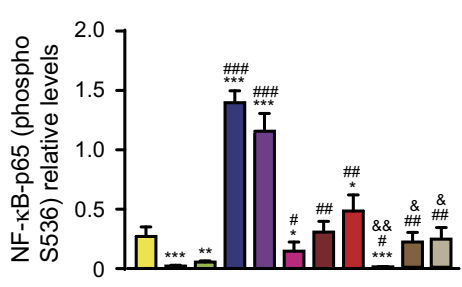

d

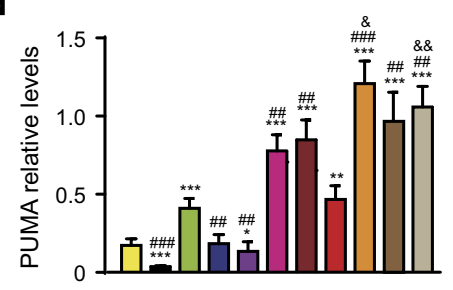

Figure 6 VD with TNF- $\alpha$ promoted p53 acetylation-mediated apoptosis in human rheumatoid FLSs. Human rheumatoid FLS-MH7A cells were treated with DMEM and 10\% FBS (serum control), DMEM (serum-free control), DMEM and indicated concentrations of VD with or without TNF- $\alpha$. (a) Western blots of cells by group for Caspase-3, Bax, Puma, Bcl-2, p53, p53 (acetyl K382), NF-kB-p65 and NF- $k$ B-p65 (phospho Ser536). $\beta$-actin was the loading control. (b-h) Protein relative to $\beta$-actin was assessed by densitometry. Values are mean \pm S.E.M. of six determinations per group. ${ }^{\star} P<0.05 ;{ }^{* \star} P<0.01 ;{ }^{* \star} P<0.001$ compared with serum-free control. ${ }^{\#} P<0.05$; ${ }^{\#} P<0.01$, ${ }^{\# \# \#} P<0.001$ compared with $10^{-7} \mathrm{M}$ VD. ${ }^{\&} P<0.05 ;{ }^{\text {\& }} P<0.01$ compared with $10 \mathrm{ng} / \mathrm{ml}$ TNF- $\alpha$ and the same concentration of VD 
a
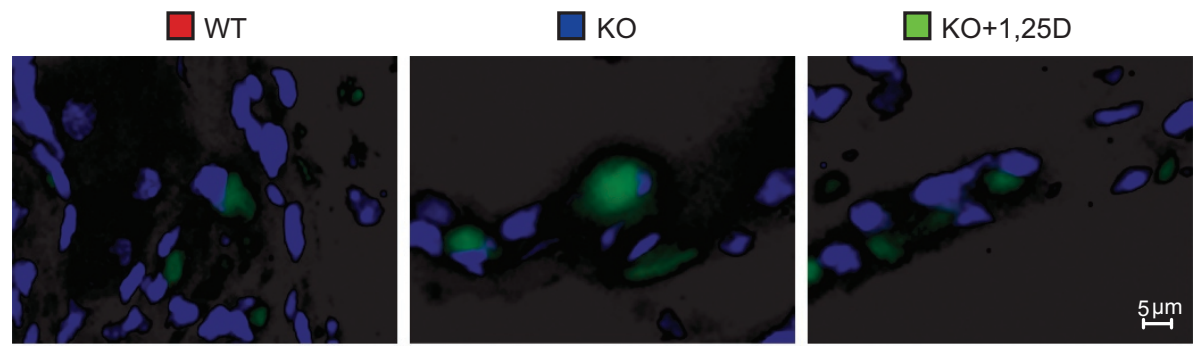

C
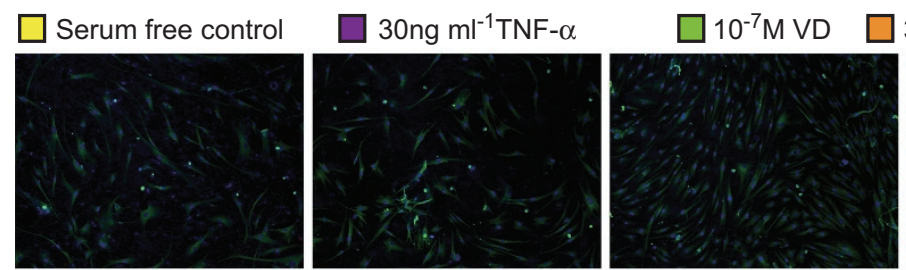

30ng $\mathrm{ml}^{-1} \mathrm{TNF}-\alpha+10^{-7} \mathrm{M}$ VD
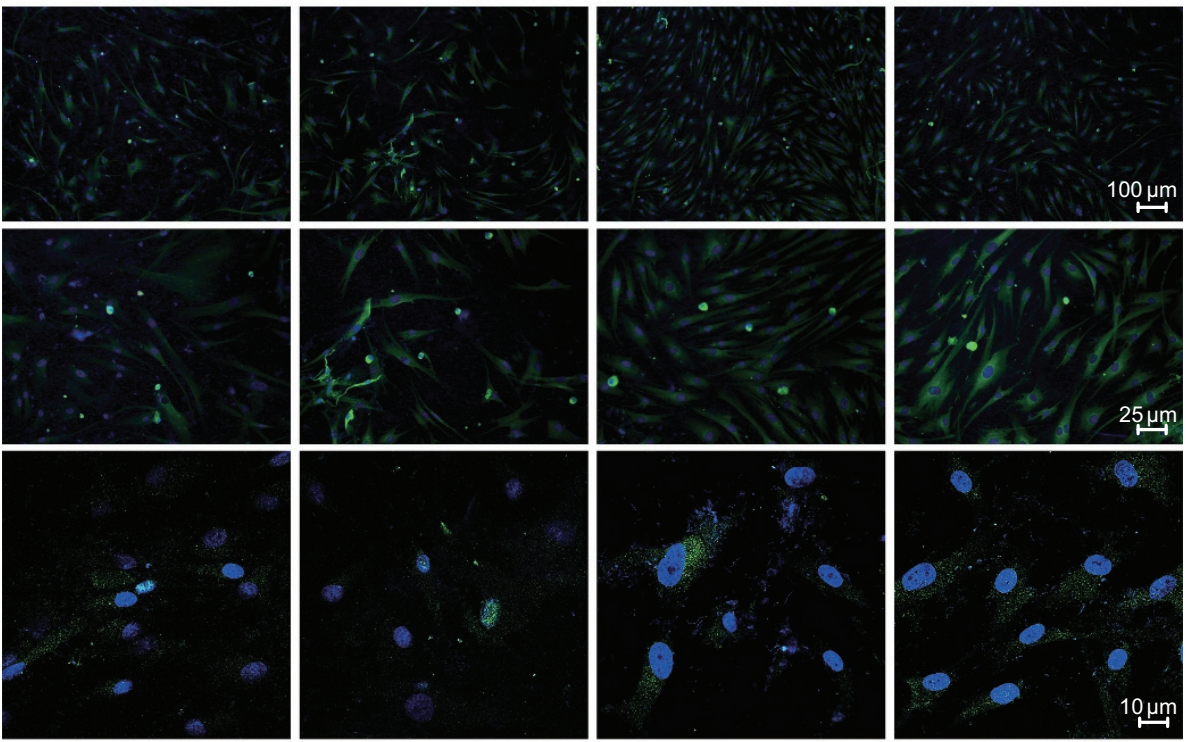

b

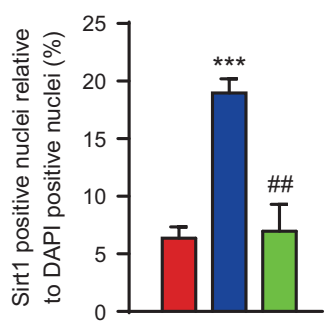

d

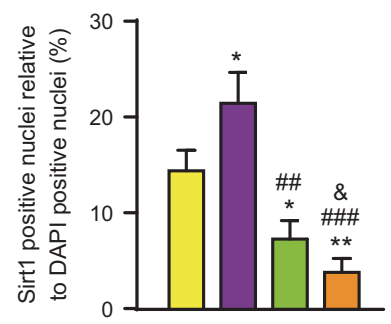

e
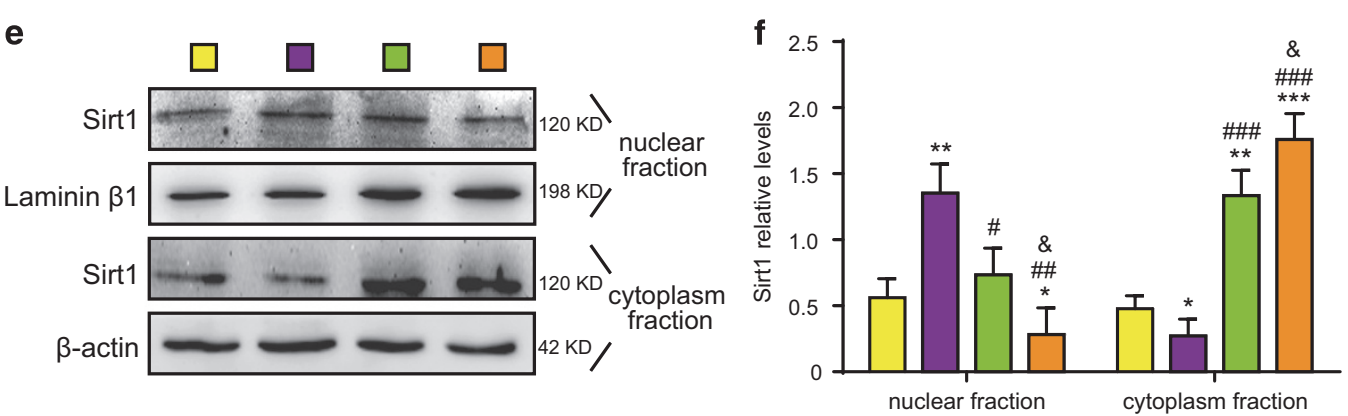

Figure 7 VD with TNF- $\alpha$ promoted SIRT1 translocation from nuclei to cytoplasm in human rheumatoid FLSs. (a) Representative micrographs of sections from paraffinembedded interphalangeal joints from 19-week-old wild type (WT), CYP27B1- ${ }^{--}$(KO) and KO+VD mice immunofluoresence in FLSs for Sirt1 (green), DAPI for nuclei (blue). Values are mean \pm S.E.M. of six determinations per group. ${ }^{* \star *} P<0.001$ compared with WT. ${ }^{\# \# ~} P<0.01$ compared with KO. (b) Percentage of Sirt1-positive nuclei relative to DAPI-positive nuclei. (c) Human rheumatoid FLS-MH7A cells treated with DMEM (serum-free control), DMEM and $30 \mathrm{ng} / \mathrm{ml} \mathrm{TNF-} \alpha\left(30 \mathrm{ng} / \mathrm{ml} \mathrm{TNF-} \alpha\right.$ ), DMEM and $10^{-7} \mathrm{M}$ VD (10${ }^{7} \mathrm{M}$ VD), DMEM and $30 \mathrm{ng} / \mathrm{ml} \mathrm{TNF}-\alpha$ and $10^{-7} \mathrm{M}$ VD (30 ng/ml TNF- $\alpha+10^{-7} \mathrm{M}$ VD). Representative micrographs of cells with immunofluoresence for Sirt1 (green) and DAPI for nuclei (blue). (d) Percentage of Sirt1-positive relative to DAPI-positive nuclei. (e) Western blots of MH7A cell nuclear fraction or cytoplasm fractions for Sirt1. Loading controls were Laminin $\beta 1$ for the nuclear fraction and $\beta$-actin for the cytoplasm fraction. Values are mean \pm S.E.M. of six determinations per group. ${ }^{*} P<0.05$; ${ }^{* *} P<0.01 ;{ }^{* \star *} P<0.001$ compared with serum-free control. ${ }^{\#} P<0.05$; ${ }^{\# \#} P<0.01$; ${ }^{\# \#} P<0.001$ compared with $30 \mathrm{ng} / \mathrm{ml}$ TNF- $\alpha$. ${ }^{\&} P<0.05$ compared with $10^{-7} \mathrm{M}$ VD 
taken using a Faxitron Model 805 radiographic inspection system (Faxitron Contact,

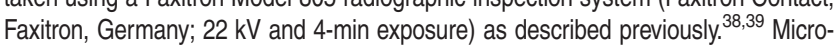
computed tomography (CT) used a SkyScan 1072 scanner and analysis software (SkyScan, Antwerp, Belgium) as described previously. ${ }^{38,39}$ Image acquisition was at $100 \mathrm{kV}$ and $98 \mathrm{~mA}$ with a 0.9 -degree rotation between frames. Two-dimensional images were used to generate three-dimensional renderings using 3D Creator software supplied with the instrument. Micro-CT image resolution is $9 \mu \mathrm{m}{ }^{38,39}$

Histochemical or immunohistochemical staining. Sections were stained with hematoxylin and eosin (HE), and total collagen labeled by picrosirius red, or Safranin $O$ and fast green double dyeing (SO-FG) (Sigma-Aldrich) as previously described. ${ }^{38,40}$

Immunohistochemical staining was performed as described previously. $37,38,41$ Serial paraffin sections were deparaffinized and dehydrated. For antigen retrieval, sections were steamed for 10-15 min in IHC Antigen Retrieval Solution $(10 x)$ (eBioscience Inc., San Diego, CA, USA) dissolved in deionized water followed by blocking of endogenous peroxidase $\left(3 \% \mathrm{H}_{2} \mathrm{O}_{2}\right)$ and preincubation with serum. Primary antibodies against TNF- $\alpha$, interleukin (IL)-1 $1 \beta$, CD3, F4/80 (Santa Cruz Biotechnology, Inc., Dallas, TX, USA), PCNA (Dako Cytomation Denmark A/S, Glostrup, Copenhagen, Denmark), Caspase3 and Sirt1 (Cell Signaling Technology, Beverly, MA, USA) were used. After washing, sections were incubated with secondary antibody (biotinylated immunoglobulin G; Sigma-Aldrich), washed, and processed using Vectastain ABC-HRP kits (Vector Laboratories Inc., Burlingame, CA, USA). Sections were counterstained with hematoxylin and mounted with biomount medium. ${ }^{37,38}$ For immunofluorescence, affinity-purified Alexa Fluor 488-conjugated secondary antibody (Life Technologies Corporation, Carlsbad, CA, USA) was used. Nuclei were labeled by DAPI (Sigma-Aldrich) and mounted with medium to prevent quenching (Vector Laboratories Inc.). . $^{38,41}$

TUNEL assay. Dewaxed and rehydrated paraffin sections were stained with an In Situ Cell Death Detection Kit (Roche Diagnostics Corp., Basel, Switzerland) using a previously described protocol. ${ }^{37,38}$

Cell lines and cell cultures. MH7A (human rheumatoid FLSs) and normal FLSs (American Type Culture Collection, Manassas, VA, USA) were cultured in DMEM supplemented with $10 \%$ FBS (Gibco, Carlsbad, CA, USA), $100 \mathrm{U} / \mathrm{ml}$ penicillin and $100 \mu \mathrm{g} / \mathrm{ml}$ streptomycin (Gibco) at $37^{\circ} \mathrm{C}$ in a humidified atmosphere of $5 \% \mathrm{CO}_{2}$ as previously described. ${ }^{14}$

Administration of VD, TNF- $a$ or PFT- $a$ in vitro. MH7A cells were treated with DMEM for $24 \mathrm{~h}$, then with DMEM and $10^{-6}, 10^{-7}, 5 \times 10^{-8}, 10^{-8}$ or $10^{-9}$ M VD (Sigma-Aldrich) for $48 \mathrm{~h}$.

MH7A cells were treated with DMEM for $24 \mathrm{~h}$, then with DMEM and $5,10,20,30$ or $40 \mathrm{ng} / \mathrm{ml} \mathrm{TNF}-\alpha$ (Novoprotein Scientific Inc., Shanghai, China) treatment for $48 \mathrm{~h}$. MH7A cells were treated with DMEM for $24 \mathrm{~h}$, then with DMEM and $5,10,20,30$ or $40 \mu \mathrm{M}$ pifithrin- $\alpha$ (PFT- $\alpha$ ) (Sigma-Aldrich) (a p53 pro-apoptotic inhibitor) for $48 \mathrm{~h}$.

Normal FLSs were treated with DMEM for $72 \mathrm{~h}$ or DMEM and $10^{-7} \mathrm{M}$ VD and/or 10 or $30 \mathrm{ng} / \mathrm{ml}$ TNF- $\alpha$ (Sigma-Aldrich) for $24 \mathrm{~h}$.

Small interference RNA-mediated knockdown of human Vitamin D receptor. For small interference RNA (siRNA) experiments, RNA primers complementary to human VDR were designed and synthesized (Ribobio Co. Ltd., Guangzhou, China). siRNAs were transfected using Lipofectamine 2000 reagent (Invitrogen, Carlsbad, CA, USA) according to the manufacturer's instructions. ${ }^{37}$ After incubation for $72 \mathrm{~h}, \mathrm{MH} 7 \mathrm{~A}$ cells were harvested and mRNA was detected by realtime RT-PCR. Sequences of siRNAs and targeted mRNAs are in Supplementary Table S2.

Cytotoxicity tests by cell counting Kit- 8 assays. MH7A cells $\left(5 \times 10^{4}\right.$ per $\mathrm{ml}, 100 \mu \mathrm{l}$ ) were plated into 96-well plates with five parallel wells per group. After $12 \mathrm{~h}$ in DMEM with FBS, cells were treated with DMEM without FBS for $24 \mathrm{~h}$, then with indicated concentrations of VD, TNF- $\alpha$, PFT- $\alpha$, human VDR siRNA, or negative control (NC) and positive control (PC) siRNA. After $48 \mathrm{~h}$, cell viability was determined by cell counting kit-8 (CCK-8) assay kits (Lot C0038) (Beyotime Institute of Biotechnology, Shanghai, China) and detected by spectrophotometry at $450 \mathrm{~nm}$ absorbance following manufacturer's instructions. ${ }^{42}$

Viability of cells treated with VD, TNF- $\alpha$, PFT- $\alpha$, human VDR siRNA, NC and PC siRNA was normalized to the serum-free control (Supplementary Figure S1B).
Flow cytometry for apoptosis. Percentage of apoptotic cells was determined by flow cytometry using FITC Annexin V Apoptosis Detection Kits I (Lot 556547) (BD Biosciences, San Jose, CA, USA) following manufacturer's instructions. The number of cells stained with annexin $\mathrm{V}$ (AV)-fluorescein isothiocyanate (FITC) and propidium iodide (PI) was assessed by flow cytometer (BD FACScan, Franklin Lakes, NJ, USA). Early apoptotic cells were defined as positive for AV-FITC but negative for PI staining; late apoptotic cells were positive for both AV-FITC and PI; and total apoptotic cells were positive for AV and positive or negative for $\mathrm{PI}^{43}$

Immunocytochemical staining. For immunocytochemical staining, cells seeded on coverslips were fixed with PLP solution for $45 \mathrm{~min}$ and pre-incubated with serum. Primary antibodies against Sirt1 (Cell Signaling Technology) and affinitypurified Alexa Fluor 488-conjugated secondary antibody (Life Technologies Corporation) were used. Nuclei were labeled with DAPI (Sigma-Aldrich) and mounted with medium to prevent quenching (Vector Laboratories Inc.). ${ }^{37,38}$

RNA isolation and Real-time RT-PCR. RNA was isolated from MH7A cells using TRIzol reagent (Invitrogen) according to the manufacturer's protocol. Sample mRNA levels were quantified by real-time RT-PCR and calculated as ratio to GAPDH mRNA as previously described. ${ }^{37,41}$ PCR primers are in Supplementary Table S3.

Western blots. Western blots using MH7A cells were performed as previously described. ${ }^{37}$ Nuclear and cytoplasm fractions of MH7A cells were extracted using NE-PER Nuclear and Cytoplasmic Extraction Reagents (Pierce Biotechnology, Rockford, IL, USA) according to the manufacturer's protocol. Primary antibodies were against Caspase3 (Cell Signaling Technology), Bax (Santa Cruz Biotechnology), Puma (Abcam, Cambridge, MA, USA), Bcl-2 (Santa Cruz Biotechnology), p53 (Cell Signaling Technology), p53(acetyl K382) (Abcam), NF-kB p65 (Cell Signaling Technology), NF- $\kappa$ B-p65 (phospho S536) (Abcam), Sirt1 (Cell Signaling Technology), VDR (Santa Cruz Biotechnology), Laminin $\beta 1$ (Abcam) or $\beta$-actin (Bioworld Technology, St. Louis Park, MN, USA). Laminin $\beta 1$ was the loading control for the nuclear fraction and $\beta$-actin for the cytoplasm fraction and total cell protein.

Statistical analysis. All analyses were performed using SPSS software (Version 16.0, SPSS Inc., Chicago, IL, USA) as previously described. ${ }^{37,38}$ Measurement data were described as mean \pm S.E.M. fold-change over control and analyzed by Student's t-test and one-way ANOVA to compare differences among groups. Qualitative data were described as percentages and analyzed using chi-square tests as indicated. $P$-values were two-sided and less than 0.05 was considered statistically significant.

\section{Conflict of Interest}

The authors declare no conflict of interest.

Acknowledgements. This work was supported by grants from the National Natural Science Foundation of China (81200491 and 81571371), and the Natural Science Foundation of Jiangsu (BK20151554) to J.J.; National Basic Research Program of China (2012CB966902 and 2014CB942900), and from the Basic Research Program of Chongqing (CSTC2013jcyjC00009) to D.M.; the practice innovation training program projects for the Jiangsu students in college (201410312020Z) to X.G.

1. Boissier MC, Semerano L, Challal S, Saidenberg-Kermanac'h N, Falgarone G. Rheumatoid arthritis: from autoimmunity to synovitis and joint destruction. $J$ autoimmun 2012; 39 : 222-228.

2. Song GG, Bae SC, Lee YH. Association between vitamin D intake and the risk of rheumatoid arthritis: a meta-analysis. Clin rheumatol 2012; 31: 1733-1739.

3. Sun J, Yan P, Chen Y, Chen Y, Yang J, Xu G et al. MicroRNA-26b inhibits cell proliferation and cytokine secretion in human RASF cells via the Wnt/GSK-3beta/beta-catenin pathway. Diagn pathol 2015; 10: 72

4. Bartok B, Firestein GS. Fibroblast-like synoviocytes: key effector cells in rheumatoid arthritis. Immunol rev 2010; 233: 233-255.

5. Liu H, Pope RM. The role of apoptosis in rheumatoid arthritis. Curr opin pharmacol 2003; 3 : 317-322.

6. Kawakami A, Eguchi K. Involvement of apoptotic cell death in autoimmune diseases. Med electron microsc 2002; 35: 1-8. 
7. Korb A, Pavenstadt H, Pap T. Cell death in rheumatoid arthritis. Apoptosis 2009; 14: 447-454.

8. Simsek I. TNF inhibitors for rheumatoid arthritis-a year in review. Bull NYU hosp jt dis 2011; 69: 220-224.

9. Brand DD, Latham KA, Rosloniec EF. Collagen-induced arthritis. Nat protoc 2007; 2: 1269-1275.

10. Morel J, Audo R, Hahne M, Combe B. Tumor necrosis factor-related apoptosis-inducing ligand (TRAIL) induces rheumatoid arthritis synovial fibroblast proliferation through mitogenactivated protein kinases and phosphatidylinositol 3-kinase/Akt. J biol chem 2005; 280: 15709-15718.

11. Wang J, Li C, Liu Y, Mei W, Yu S, Liu C et al. JAB1 determines the response of rheumatoid arthritis synovial fibroblasts to tumor necrosis factor-alpha. Am j pathol 2006; 169: 889-902.

12. Coussens LM, Werb Z. Inflammation and cancer. Nature 2002; 420: 860-867.

13. Christakos S, Dhawan P, Verstuyf A, Verlinden L, Carmeliet G. Vitamin D: metabolism, molecular mechanism of action, and pleiotropic effects. Physiol rev 2016; 96: 365-408.

14. Feng X, Lv C, Wang F, Gan K, Zhang M, Tan W. Modulatory effect of 1,25-dihydroxyvitamin D 3 on IL1 beta -induced RANKL, OPG, TNF alpha, and IL-6 expression in human rheumatoid synoviocyte MH7A. Clin dev immunol 2013; 2013: 160123.

15. Bogaczewicz J, Sysa-Jedrzejowska A, Arkuszewska C, Zabek J, Kontny E, McCauliffe D et al. Vitamin $\mathrm{D}$ status in systemic lupus erythematosus patients and its association with selected clinical and laboratory parameters. Lupus 2012; 21: 477-484.

16. Ruefli-Brasse AA, French DM, Dixit VM. Regulation of NF-kappaB-dependent lymphocyte activation and development by paracaspase. Science 2003; 302: 1581-1584.

17. Li H, Wan A. Apoptosis of rheumatoid arthritis fibroblast-like synoviocytes: possible roles of nitric oxide and the thioredoxin 1. Mediators inflamm 2013; 2013: 953462.

18. Zwerina K, Baum W, Axmann R, Heiland GR, Distler JH, Smolen J et al. Vitamin D receptor regulates TNF-mediated arthritis. Ann rheum dis 2011; 70: 1122-1129.

19. Dai C, Gu W. p53 post-translational modification: deregulated in tumorigenesis. Trends mol med 2010; 16: 528-536.

20. Tak PP, Smeets TJ, Boyle DL, Kraan MC, Shi Y, Zhuang S et al. p53 overexpression in synovial tissue from patients with early and longstanding rheumatoid arthritis compared with patients with reactive arthritis and osteoarthritis. Arthritis rheum 1999; 42: 948-953.

21. Salvador G, Sanmarti R, Garcia-Peiro A, Rodriguez-Cros JR, Munoz-Gomez J, Canete JD. p53 expression in rheumatoid and psoriatic arthritis synovial tissue and association with joint damage. Ann rheum dis 2005; 64: 183-187.

22. You X, Boyle DL, Hammaker D, Firestein GS. PUMA-mediated apoptosis in fibroblast-like synoviocytes does not require p53. Arthritis res ther 2006; 8: R157.

23. Sykes SM, Mellert HS, Holbert MA, Li K, Marmorstein R, Lane WS et al. Acetylation of the p53 DNA-binding domain regulates apoptosis induction. Mol cell 2006; 24: 841-851.

24. Cheng HL, Mostoslavsky R, Saito S, Manis JP, Gu Y, Patel P et al. Developmental defects and p53 hyperacetylation in Sir2 homolog (SIRT1)-deficient mice. Proc Natl Acad Sci USA 2003; 100: 10794-10799.

25. Niederer F, Ospelt C, Brentano F, Hottiger MO, Gay RE, Gay S et al. SIRT1 overexpression in the rheumatoid arthritis synovium contributes to proinflammatory cytokine production and apoptosis resistance. Ann rheum dis 2011; 70: 1866-1873.

26. Okamoto T. NF-kappaB and rheumatic diseases. Endocr metab immune disord drug targets 2006; 6: 359-372

27. Jeong SJ, Pise-Masison CA, Radonovich MF, Park HU, Brady JN. Activated AKT regulates NF-kappaB activation, p53 inhibition and cell survival in HTLV-1-transformed cells. Oncogene 2005; 24: 6719-6728.

28. Jeong SJ, Pise-Masison CA, Radonovich MF, Park HU, Brady JN. A novel NF-kappaB pathway involving IKKbeta and p65/RelA Ser-536 phosphorylation results in p53 Inhibition in the absence of NF-kappaB transcriptional activity. J biol chem 2005; 280 : 10326-10332.

29. Peng JS, Chen SY, Wu CL, Chong HE, Ding YC, Shiau AL et al. Amelioration of experimental autoimmune arthritis through targeting of synovial fibroblasts by intraarticular delivery of microRNAs 140-3p and 140-5p. Arthritis rheumatol 2016; 68: 370-381.
30. Kok SH, Lin LD, Hou KL, Hong CY, Chang CC, Hsiao M et al. Simvastatin inhibits cysteinerich protein 61 expression in rheumatoid arthritis synovial fibroblasts through the regulation of sirtuin-1/FoxO3a signaling. Arthritis rheum 2013; 65: 639-649.

31. Nakayama H, Yaguchi T, Yoshiya S, Nishizaki T. Resveratrol induces apoptosis MH7A human rheumatoid arthritis synovial cells in a sirtuin 1-dependent manner. Rheumatol int 2012; 32: 151-157.

32. Jin $Q$, Yan T, Ge X, Sun C, Shi X, Zhai Q. Cytoplasm-localized SIRT1 enhances apoptosis. $J$ cell physiol 2007; 213: 88-97.

33. Tanno M, Sakamoto J, Miura T, Shimamoto K, Horio Y. Nucleocytoplasmic shuttling of the NAD+-dependent histone deacetylase SIRT1. J biol chem 2007; 282: 6823-6832.

34. Panda DK, Miao D, Tremblay ML, Sirois J, Farookhi R, Hendy GN et al. Targeted ablation of the 25-hydroxyvitamin D 1alpha -hydroxylase enzyme: evidence for skeletal, reproductive, and immune dysfunction. Proc Natl Acad Sci USA 2001; 98: 7498-7503.

35. Liu Y, Chen L, Zhi C, Shen M, Sun W, Miao D et al. 1,25(OH)2D3 Deficiency induces colon inflammation via secretion of senescence-associated inflammatory cytokines. PloS one 2016; 11: e0146426.

36. Jimi E, Aoki K, Saito H, D'Acquisto F, May MJ, Nakamura I et al. Selective inhibition of NF-kappa B blocks osteoclastogenesis and prevents inflammatory bone destruction in vivo. Nat med 2004; 10: 617-624.

37. Jin J, Lv X, Chen L, Zhang W, Li J, Wang $Q$ et al. Bmi-1 plays a critical role in protection from renal tubulointerstitial injury by maintaining redox balance. Aging cell 2014; 13 : 797-809.

38. Xie C, Jin J, Lv X, Tao J, Wang R, Miao D. Anti-aging effect of transplanted amniotic membrane mesenchymal stem cells in a premature aging model of Bmi-1 deficiency. Sci rep 2015; 5: 13975.

39. Zhang HW, Ding J, Jin JL, Guo J, Liu JN, Karaplis A et al. Defects in mesenchymal stem cell self-renewal and cell fate determination lead to an osteopenic phenotype in Bmi-1 null mice. $J$ bone miner res 2010; 25: 640-652.

40. Wang $P$, Zhang F, He Q, Wang J, Shiu HT, Shu Y et al. Flavonoid compound icariin activates hypoxia inducible factor-1alpha in chondrocytes and promotes articular cartilage repair. PloS one 2016; 11: e0148372.

41. Jin J, Zhao Y, Tan X, Guo C, Yang Z, Miao D. An improved transplantation strategy for mouse mesenchymal stem cells in an acute myocardial infarction model. PloS one 2011; 6: e21005

42. Li L, Lin M, Li L, Wang R, Zhang C, Qi G et al. Renal telocytes contribute to the repair of ischemically injured renal tubules. J cell mol med 2014; 18: 1144-1156.

43. Shao S, Li S, Qin Y, Wang X, Yang Y, Bai H et al. Spautin-1, a novel autophagy inhibitor enhances imatinib-induced apoptosis in chronic myeloid leukemia. Int j oncol 2014; 44: 1661-1668.

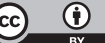

Cell Death and Disease is an open-access journal published by Nature Publishing Group. This work is licensed under a Creative Commons Attribution 4.0 International License. The images or other third party material in this article are included in the article's Creative Commons license, unless indicated otherwise in the credit line; if the material is not included under the Creative Commons license, users will need to obtain permission from the license holder to reproduce the material. To view a copy of this license, visit http://creativecommons.org/licenses/by/4.0/

(C) The Author(s) 2016

Supplementary Information accompanies this paper on Cell Death and Disease website (http://www.nature.com/cddis) 